\title{
De la invasión al barrio
}

Fontcuberta Rubio, David

2. Universidad de Alicante, Departamento de Expresión Gráfica y Cartografía, Escuela Politécnica Superior, Alicante, España, davidfontcuberta@gmail.com

Villar Pastor, Paula

3. Universidad de Alicante, Departamento de Expresión Gráfica y Cartografía, Escuela Politécnica Superior, Alicante, España, paula_v_p@msn.com

PROYECTO FIN DE CARRERA

De la invasión al barrio. 

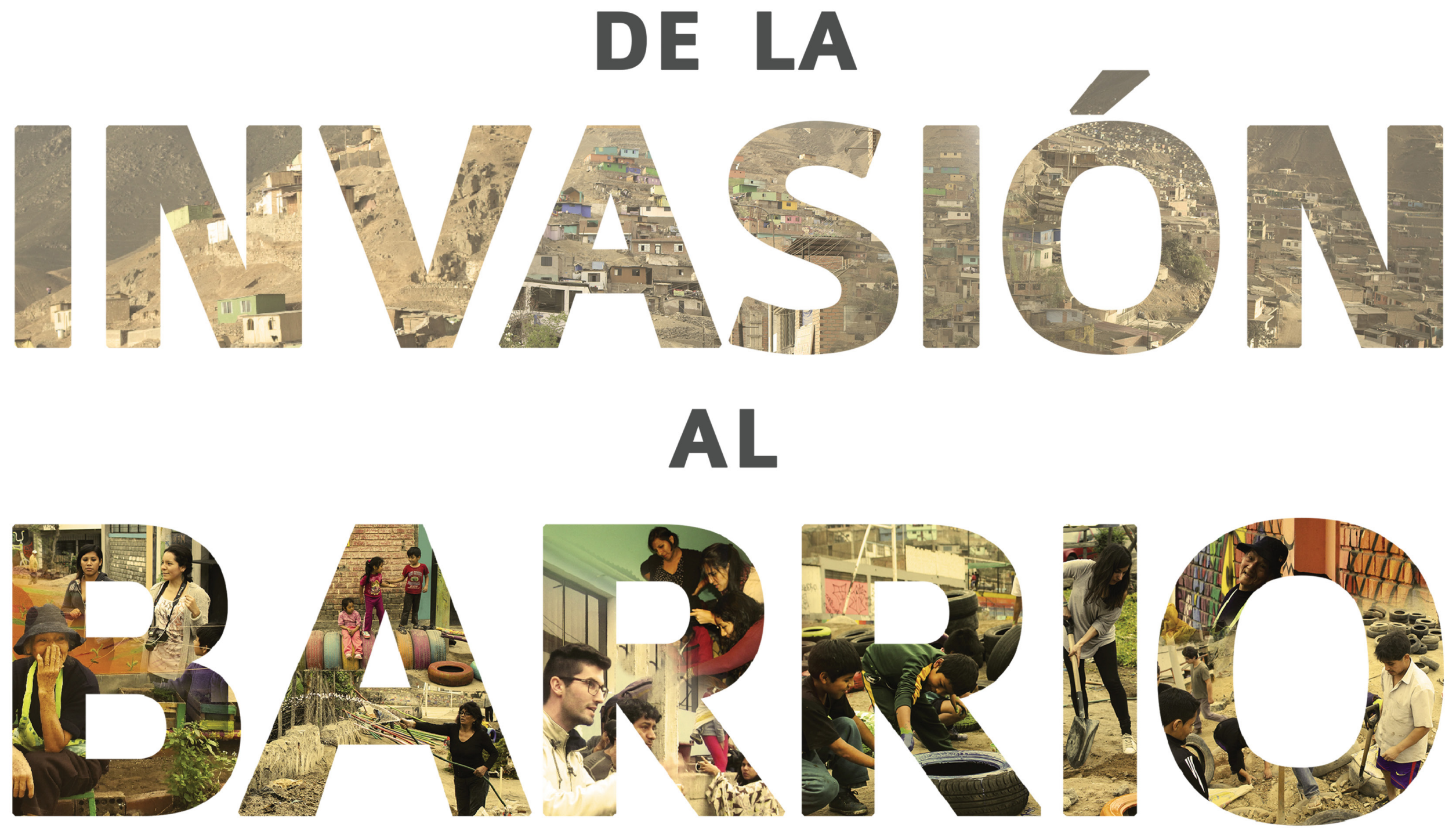

PROYECTO FINAL DE CARRERA · AROUITECTURA DAVID FONTCUBERTA · PAULA VILLAR 


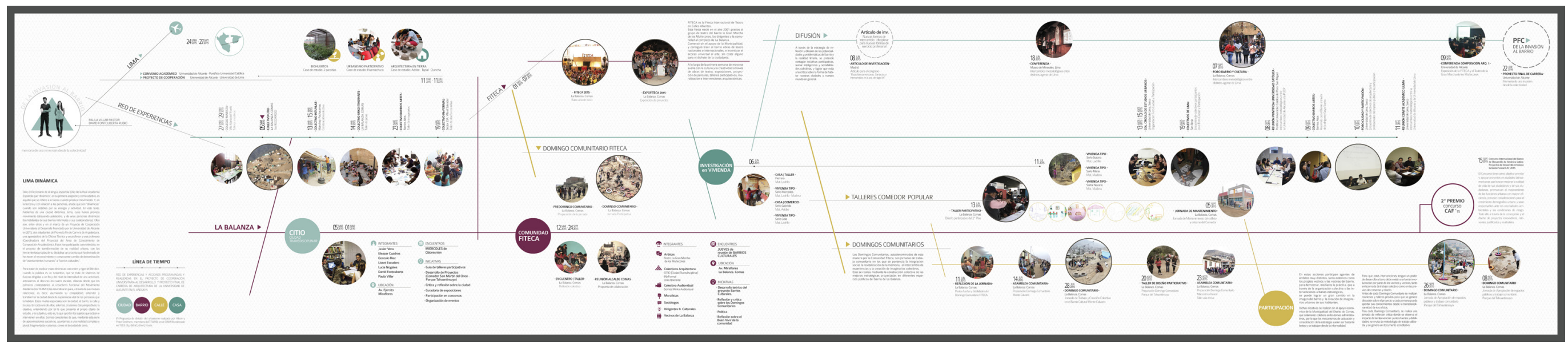

[...] Por muy dura y amarga, por muy embarazosa y amenazadora que sea la carestía de viviendas, la auténtica penuria del habitar no consiste en primer lugar en la falta de viviendas. [...] La auténtica penuria del habitar descansa en el hecho de que los mortales primero tienen que volver a buscar la esencia del habitar, de que tienen que aprender primero a habitar. [...] Llevarán a cabo esto cuando construyan desde el habitar y piensen para el habitar. 

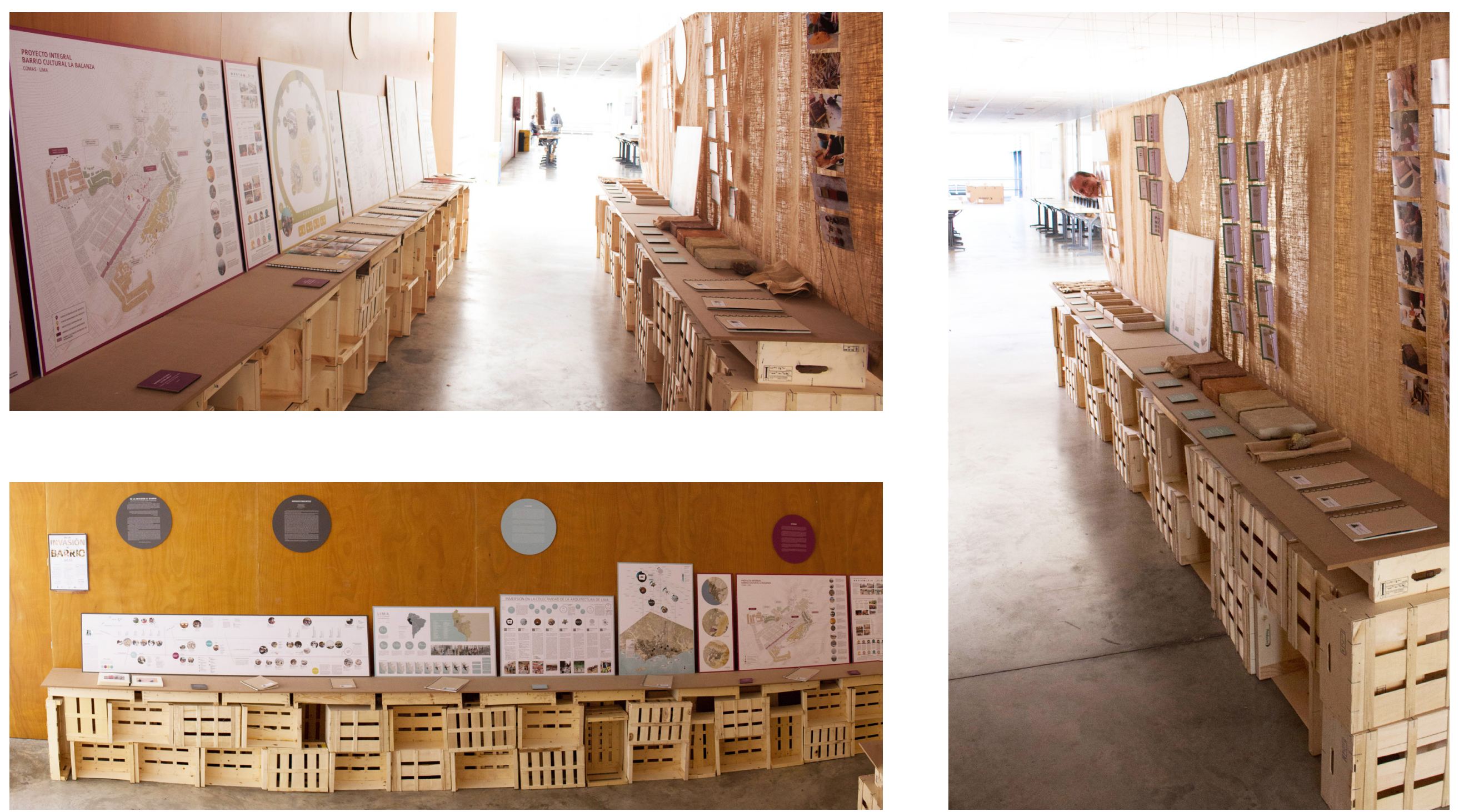


\section{L/I/M/A. \\ CIUDAD(anía)}

FRAGMENTADA

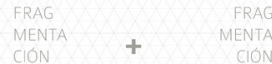

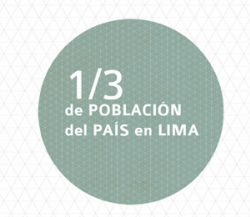

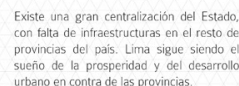

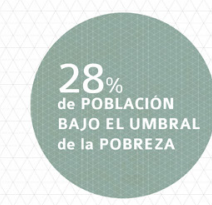

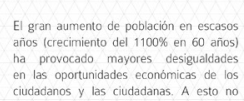

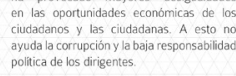
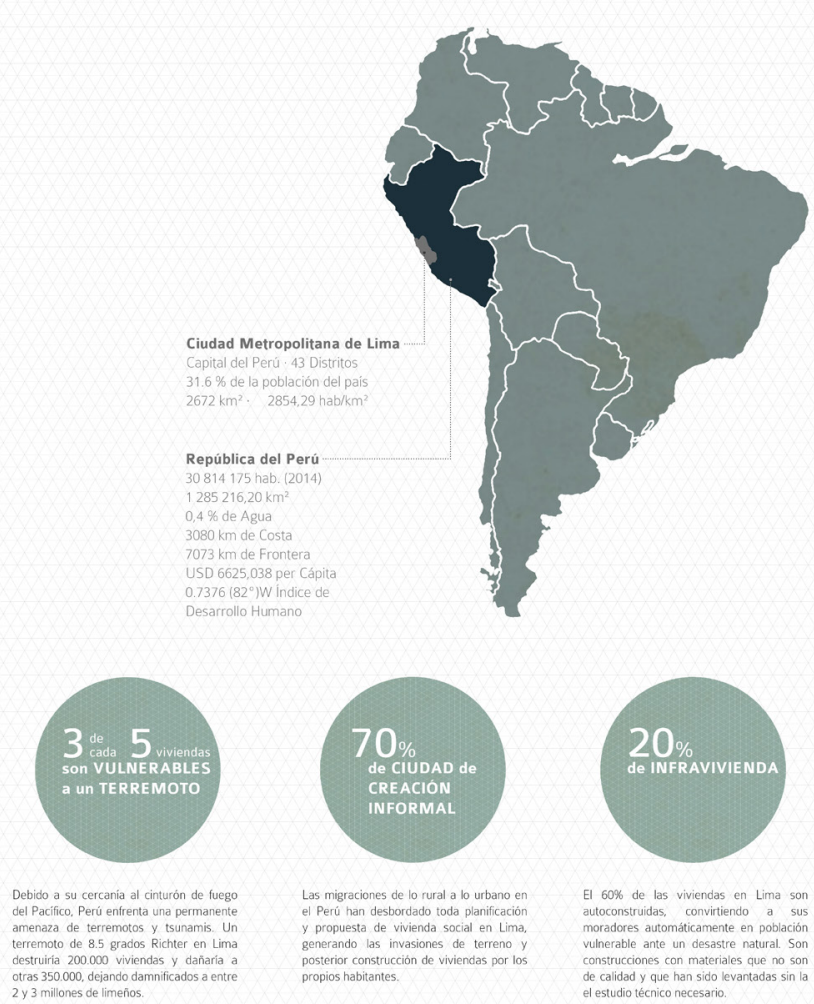
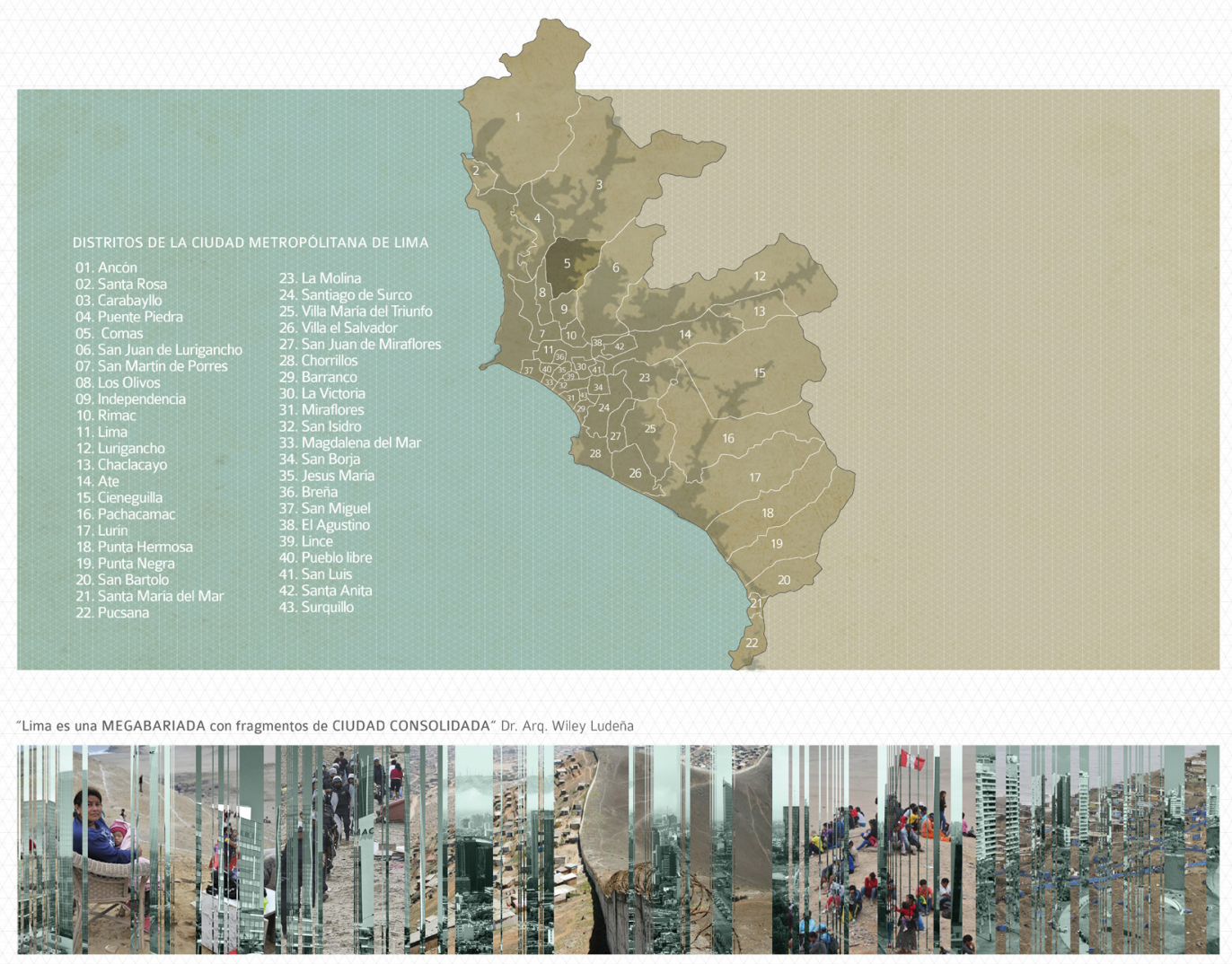

EVOLUCIÓN HISTORICA
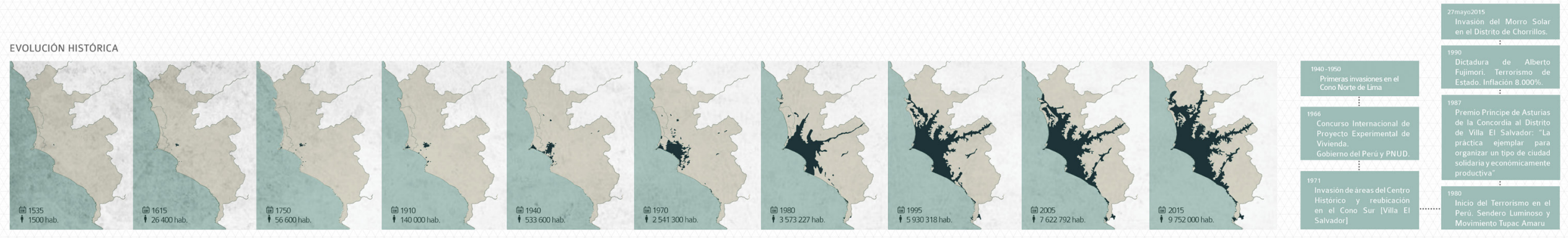
INMERSIÓN EN LA COLECTIVIDAD DE LA ARQUITECTURA DE LIMA

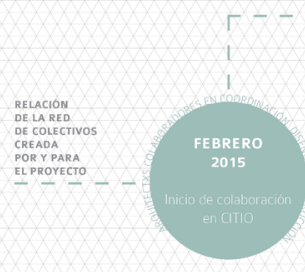

(1)

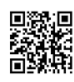

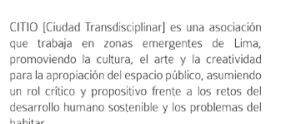

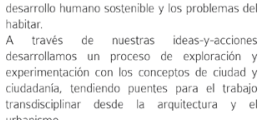

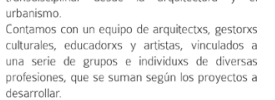

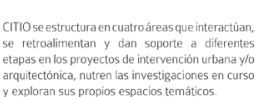

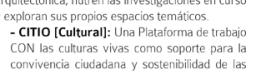

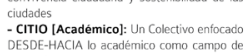

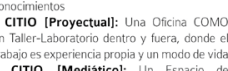

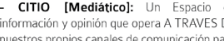

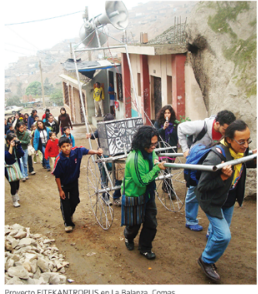

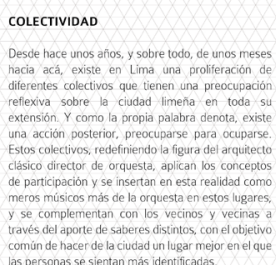
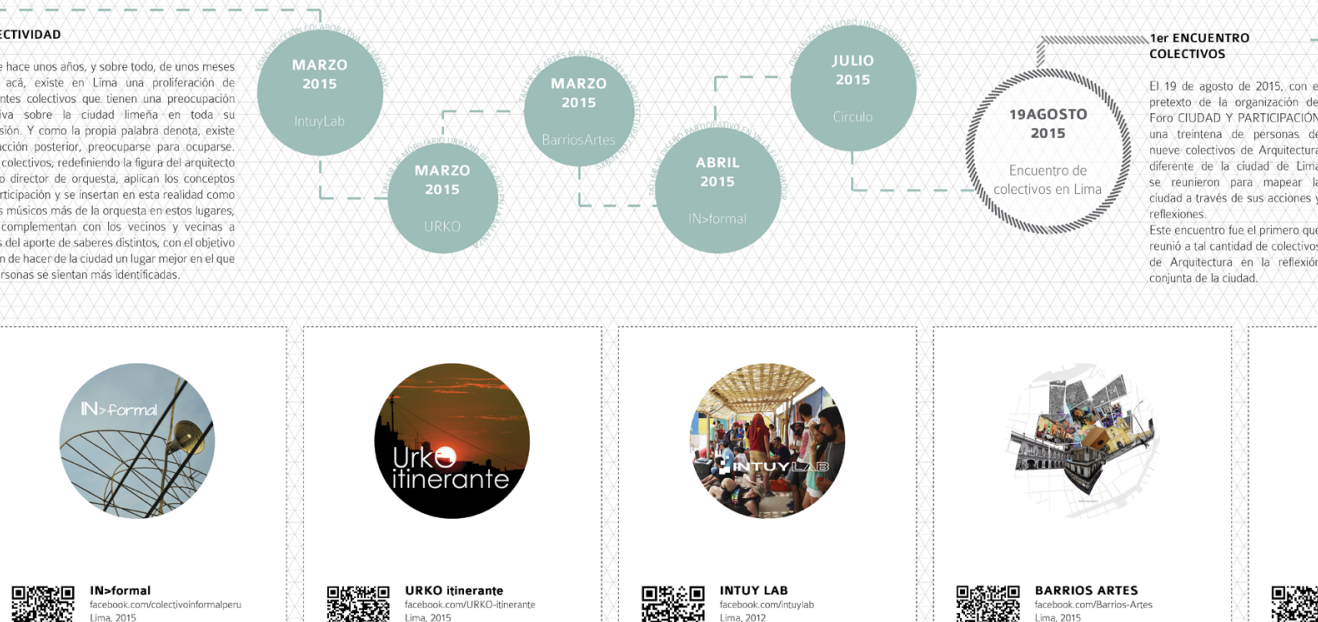

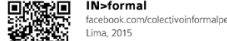
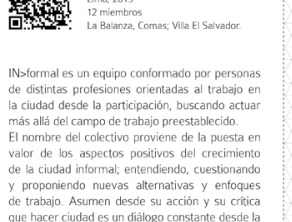

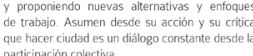

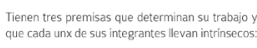

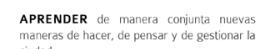

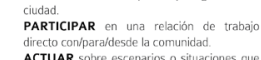

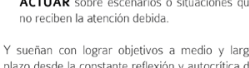

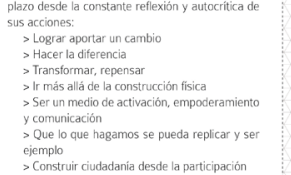

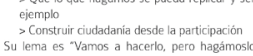

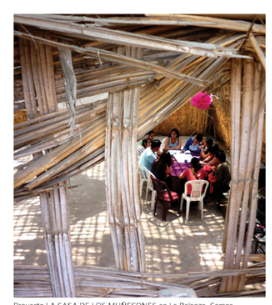

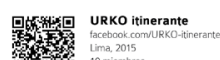

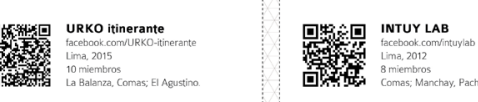

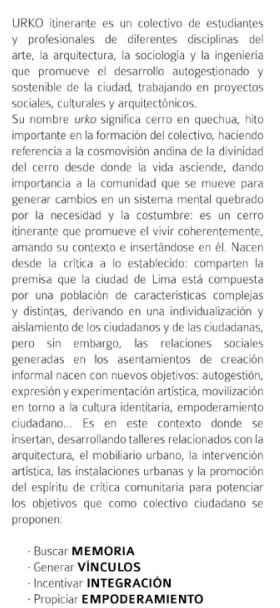

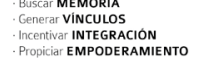

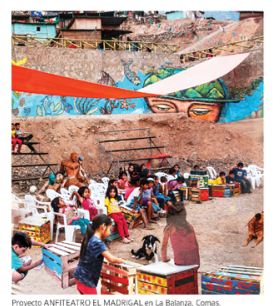

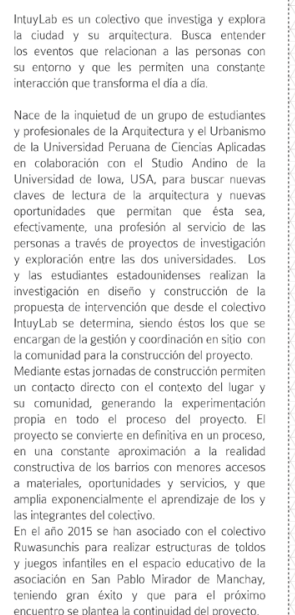

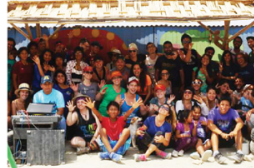

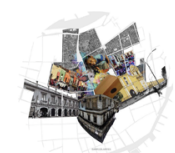
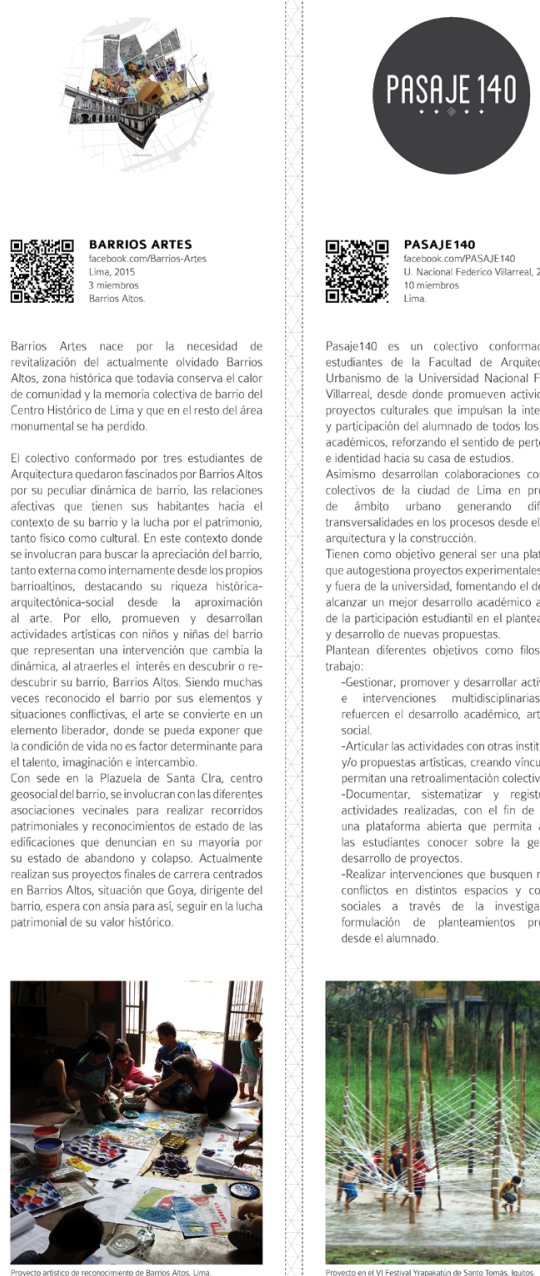
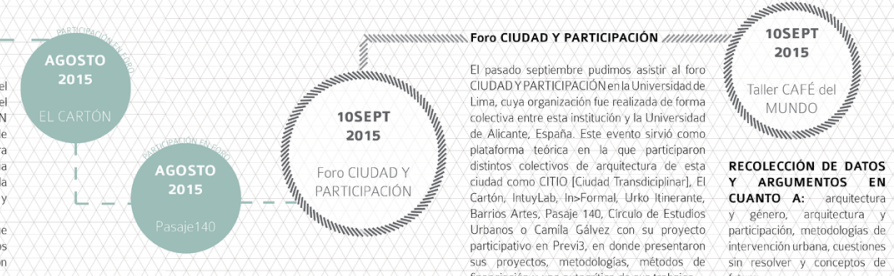

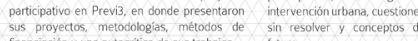
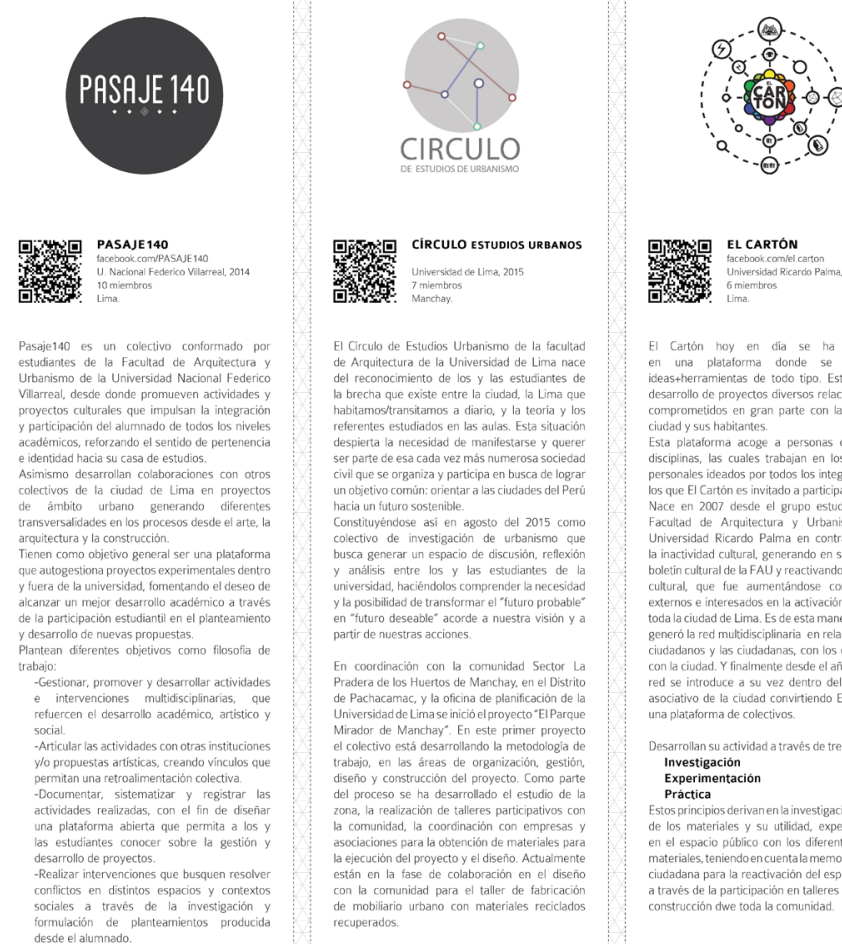

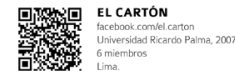
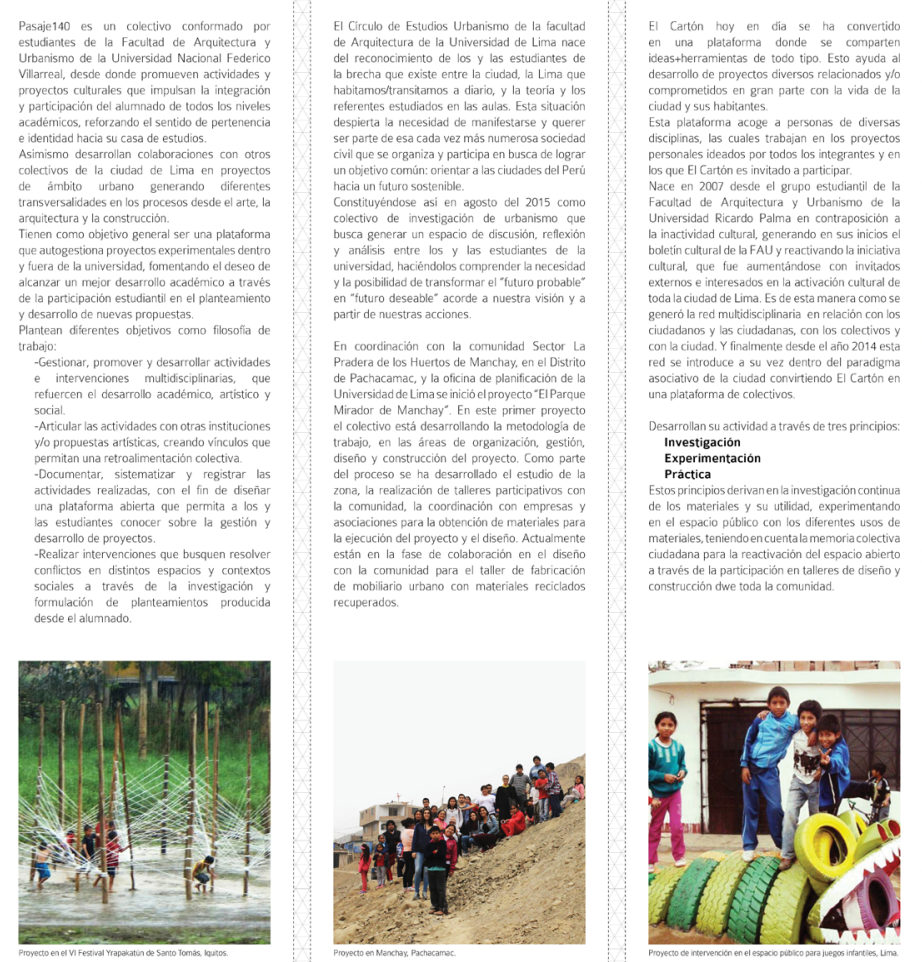

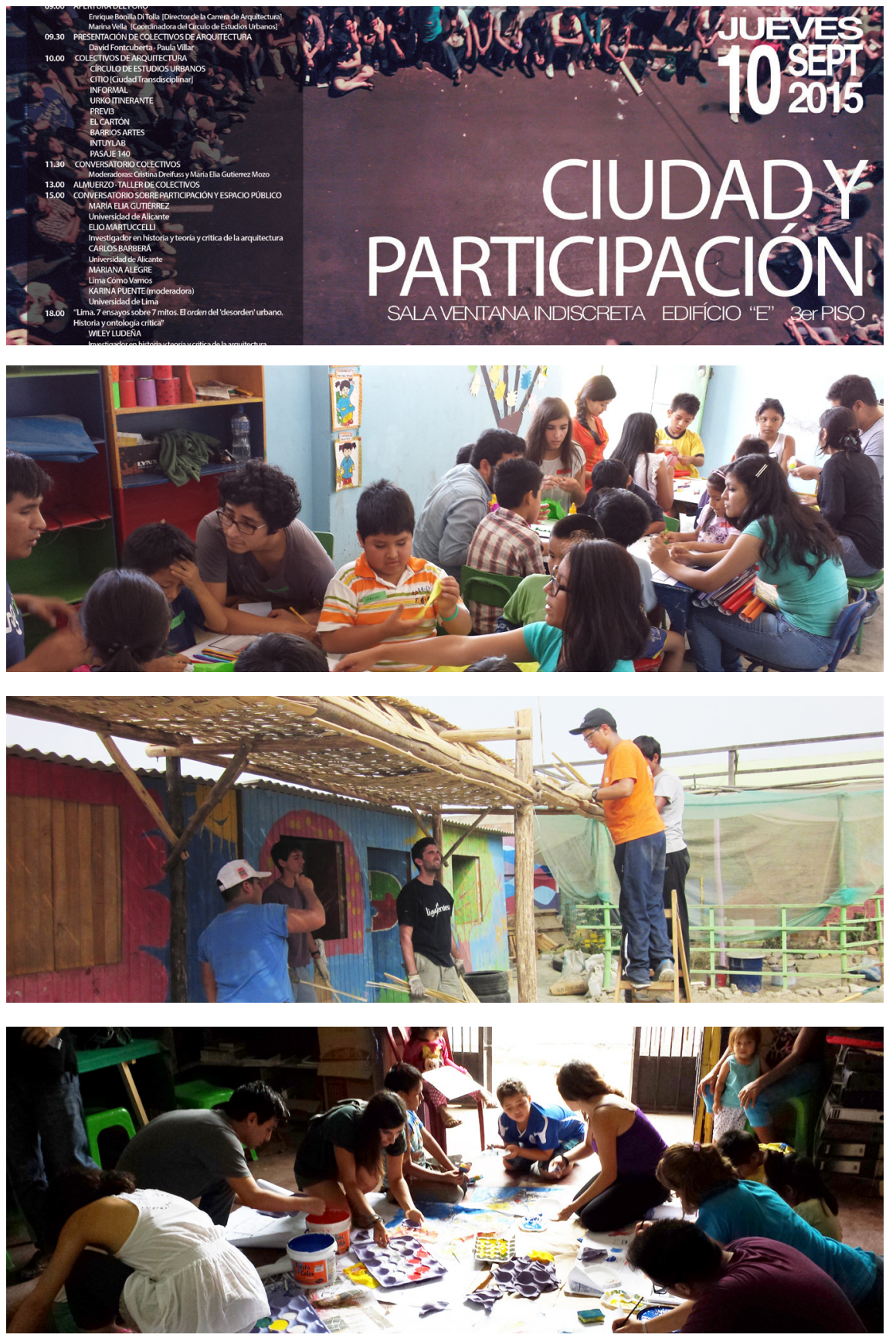

Conocimiento de diferentes modos de actuar y colaborar en la ciudad de Lima a través de los colectivos de arquitectura existentes en la ciudad.

|Febrero · septiembre 2015|

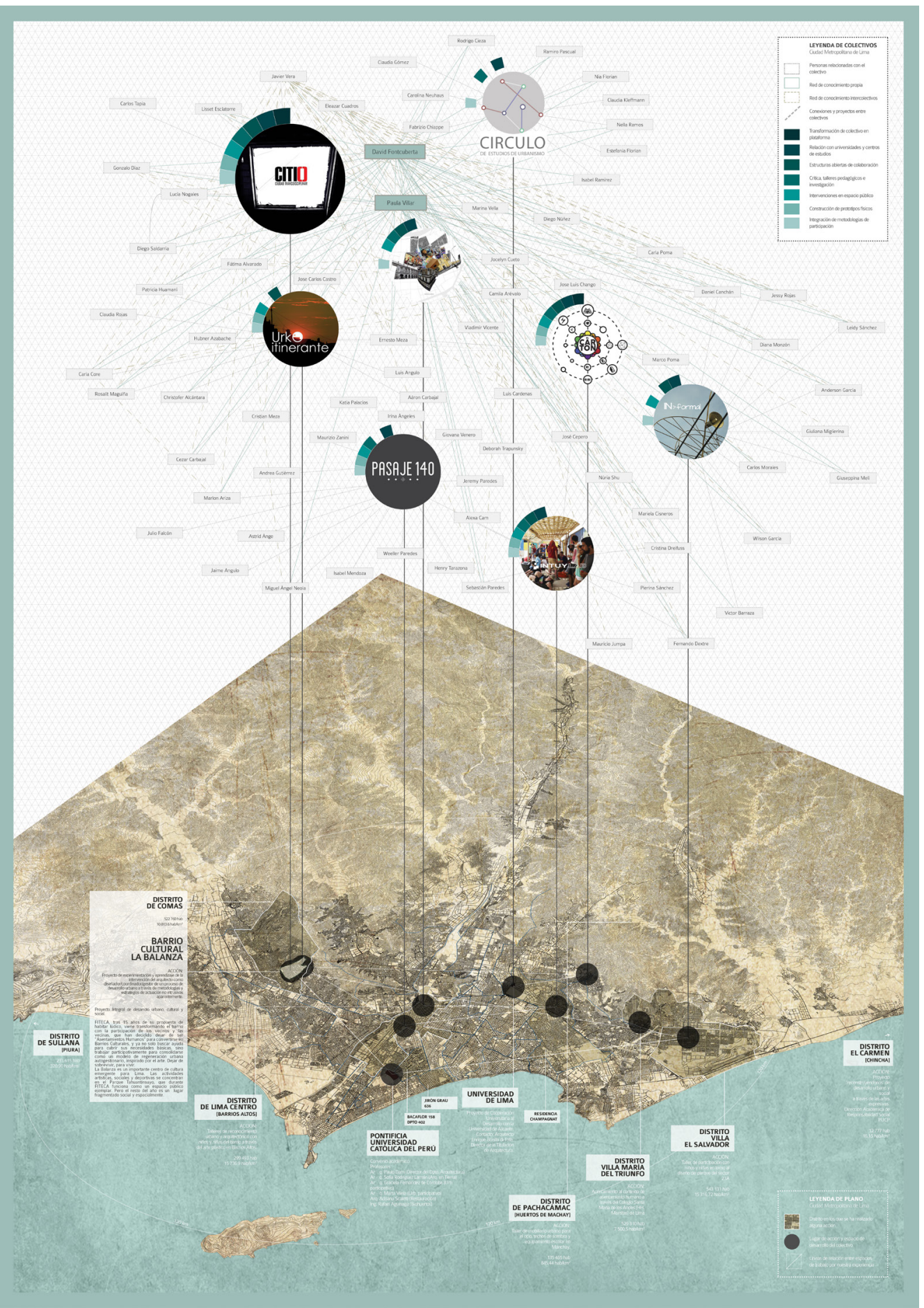



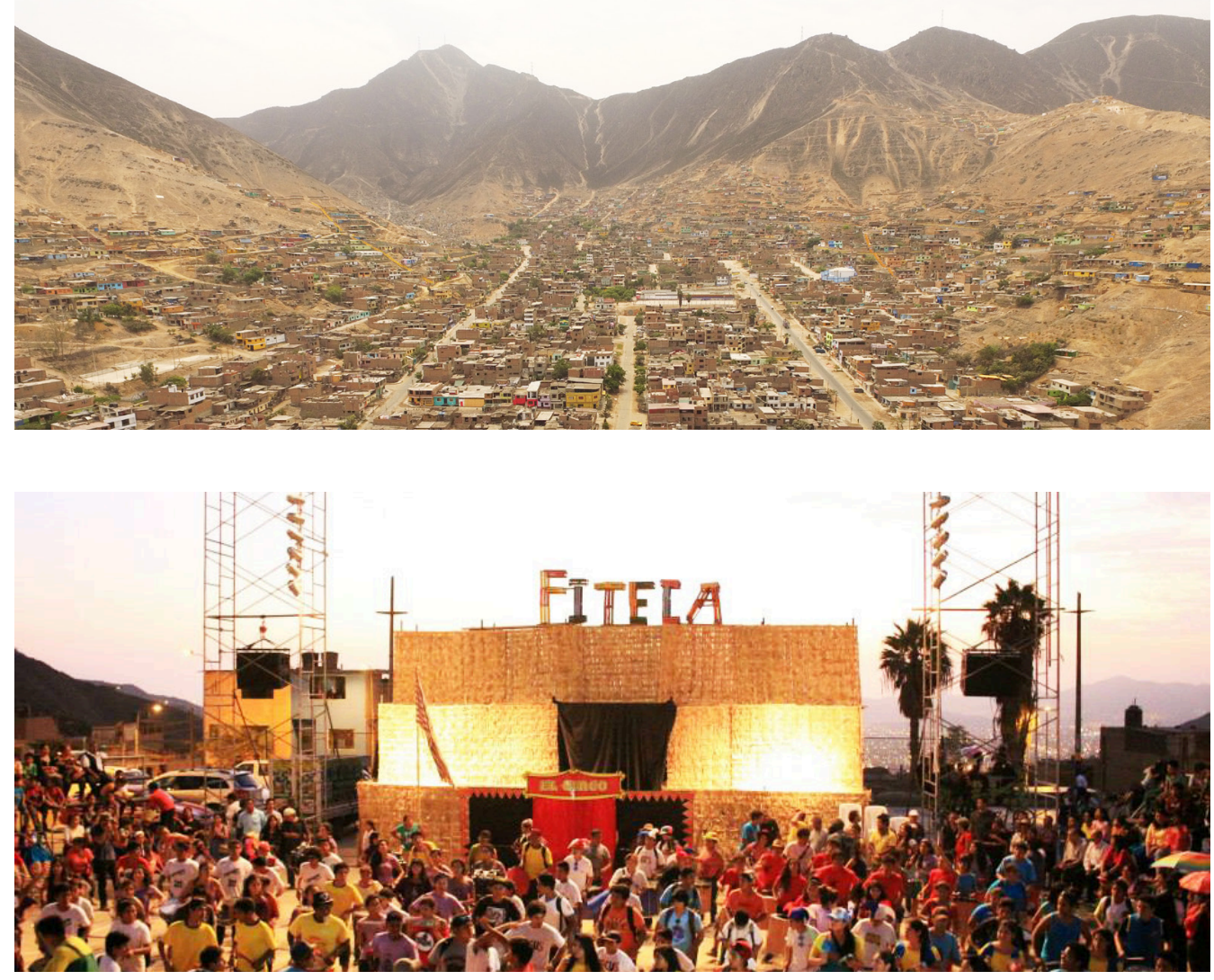

BARRIO CULTURAL LA BALANZA |Lima|

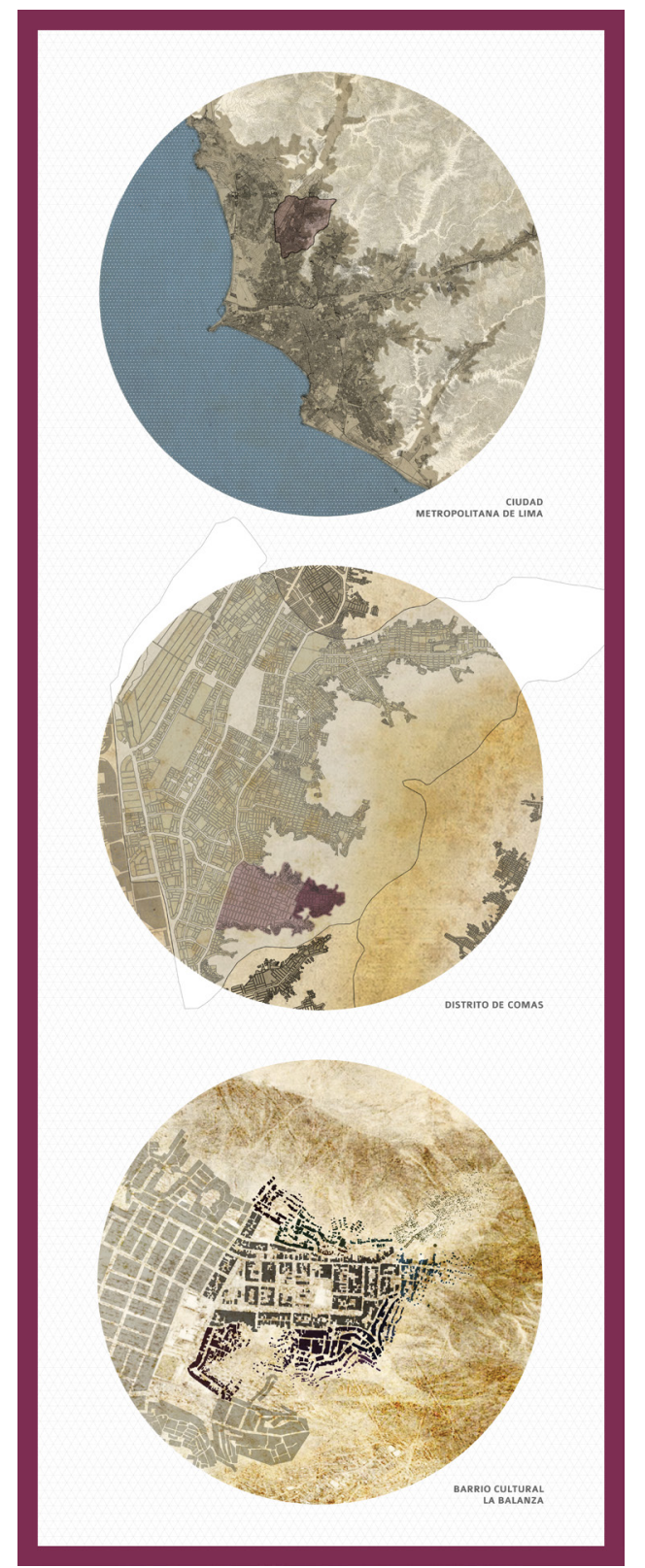

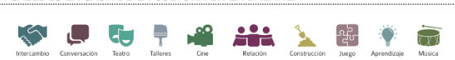

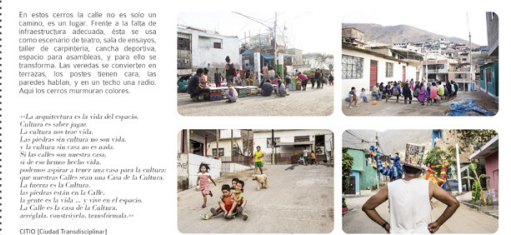

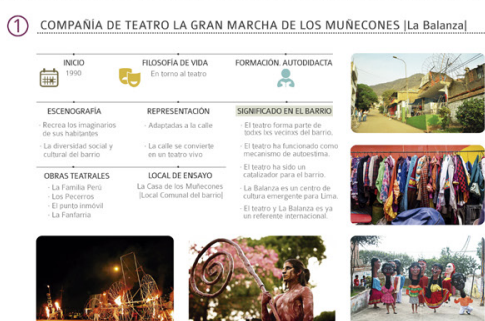

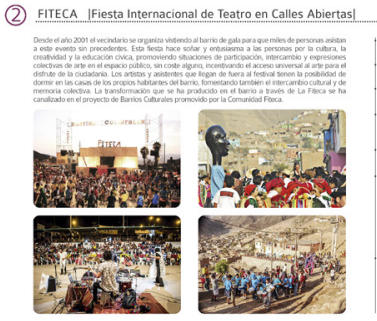

요요 요

(2) 앙 응 $-1$ 
PROYECTO INTEGRAL

BARRIO CULTURAL LA BALANZA

COMAS - LIMA

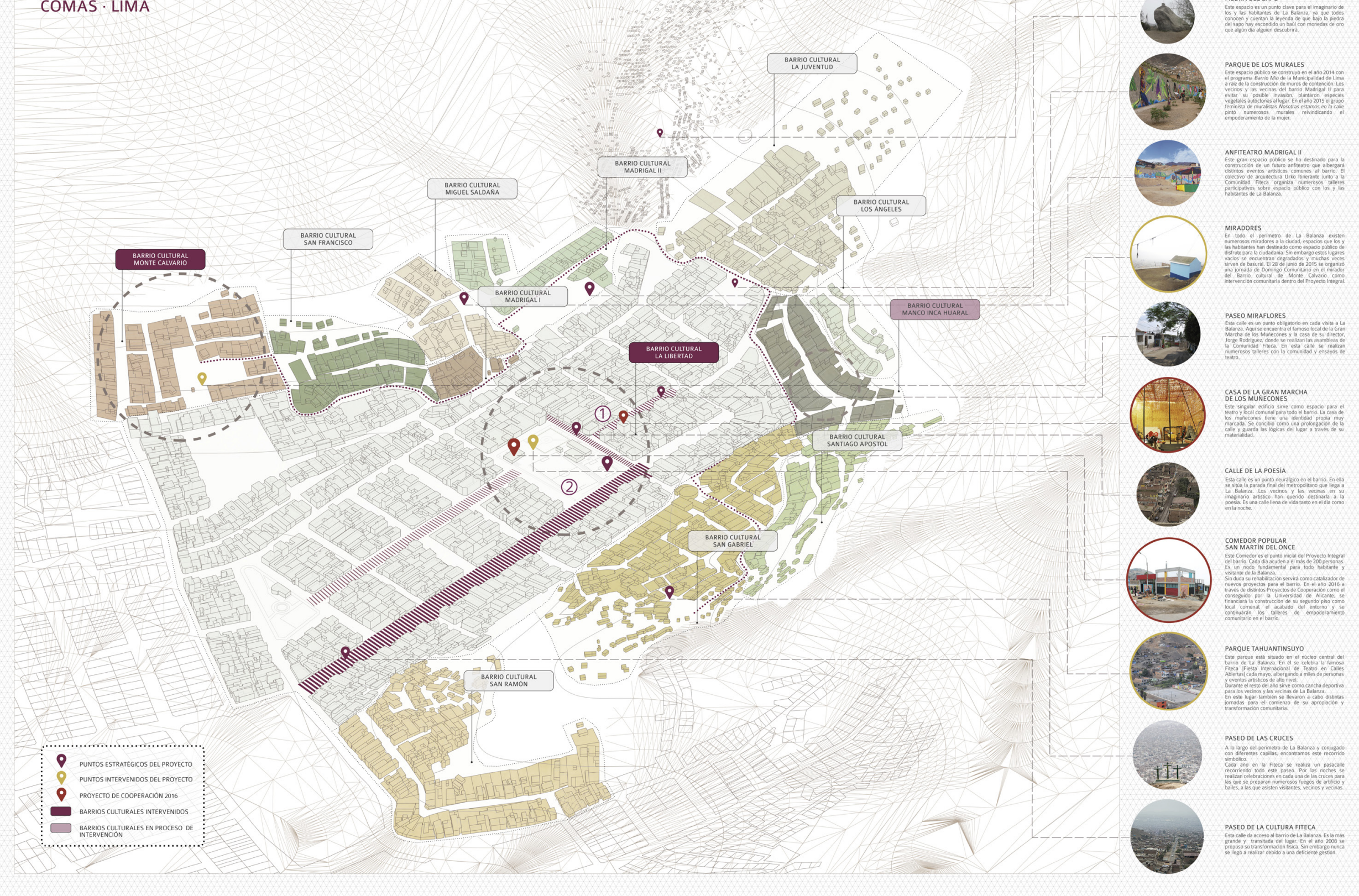



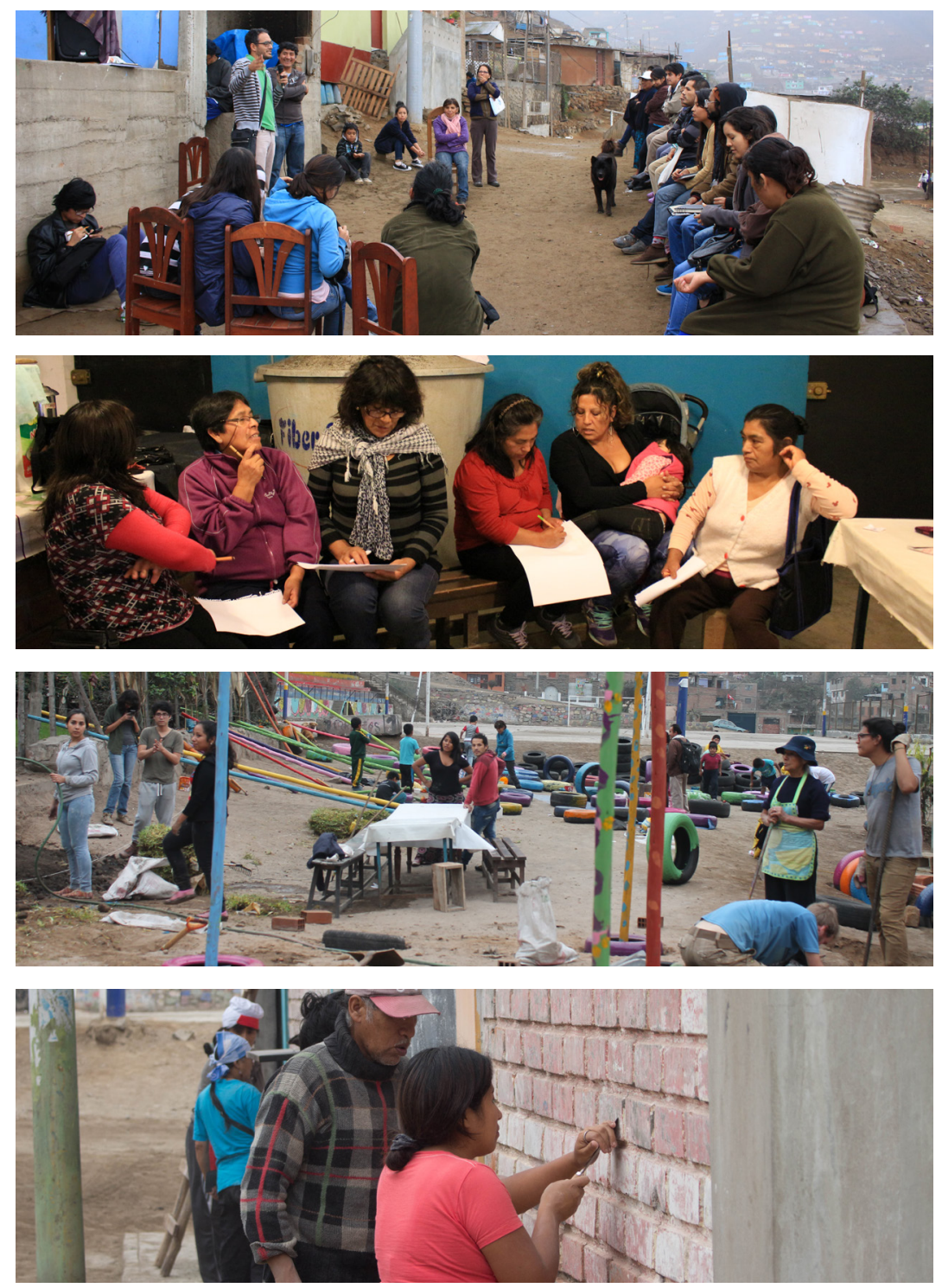

Metodología de actuación en el Barrio cultural La Balanza. |Marzo · octubre 2015|

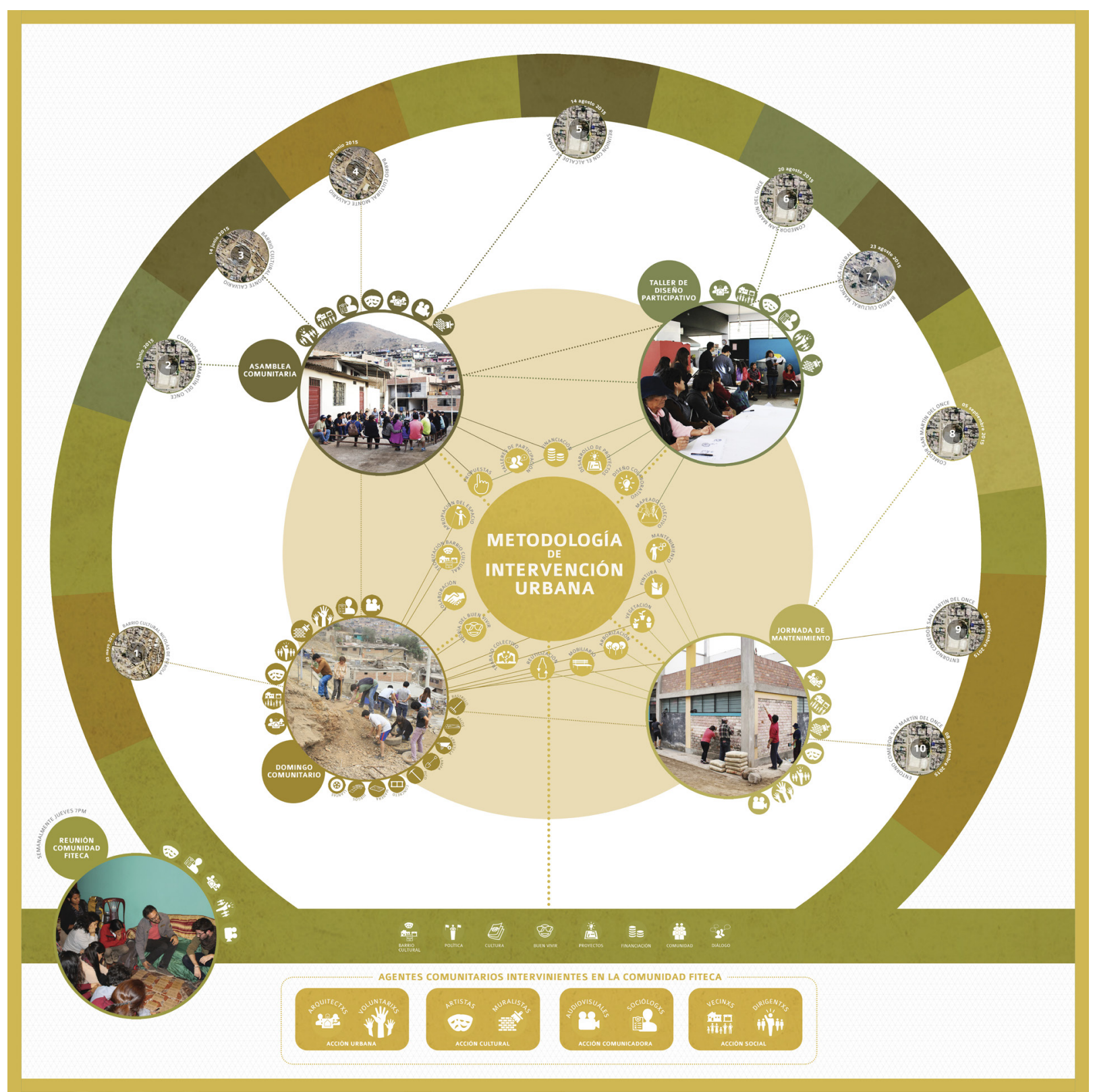



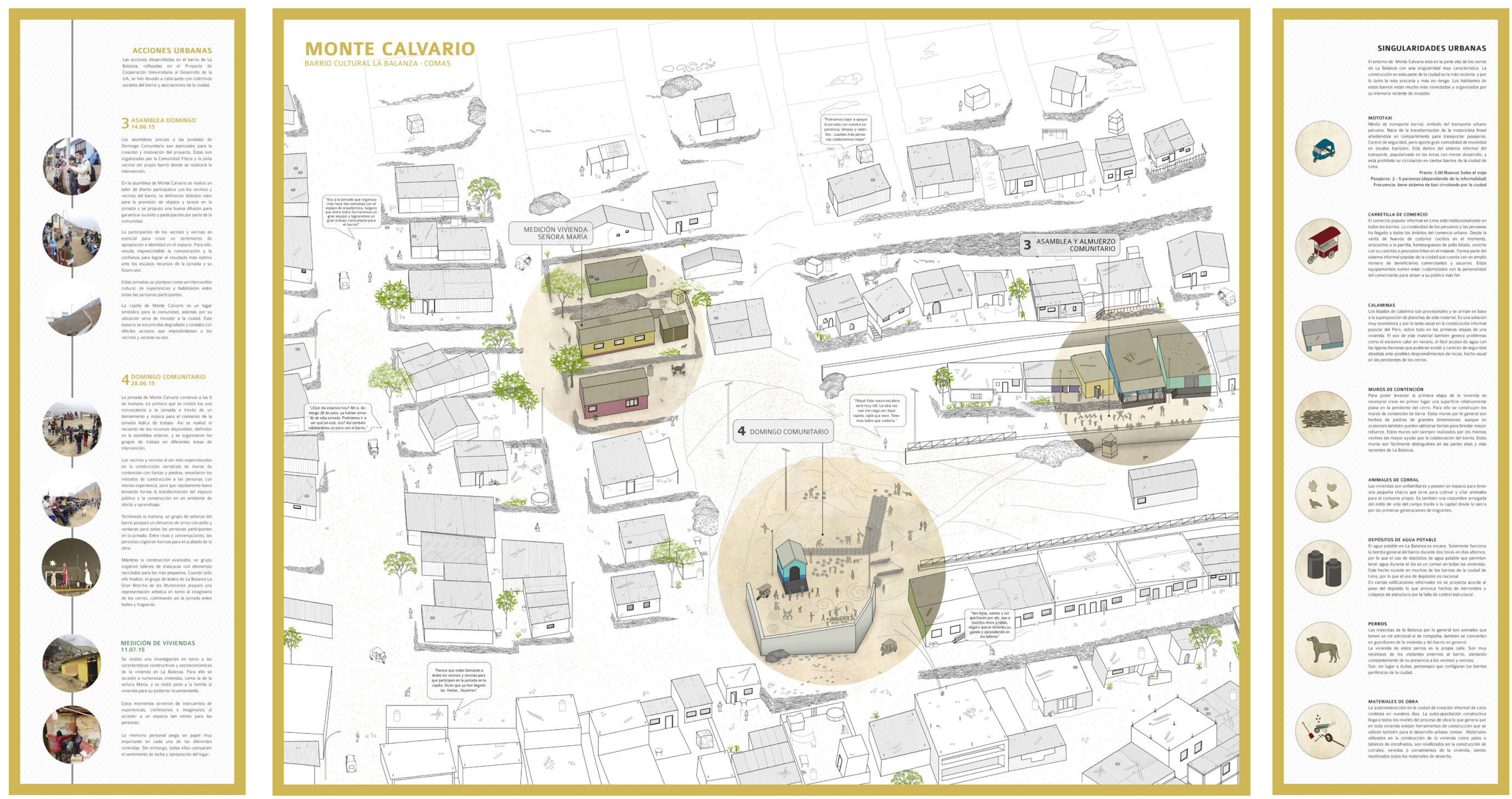


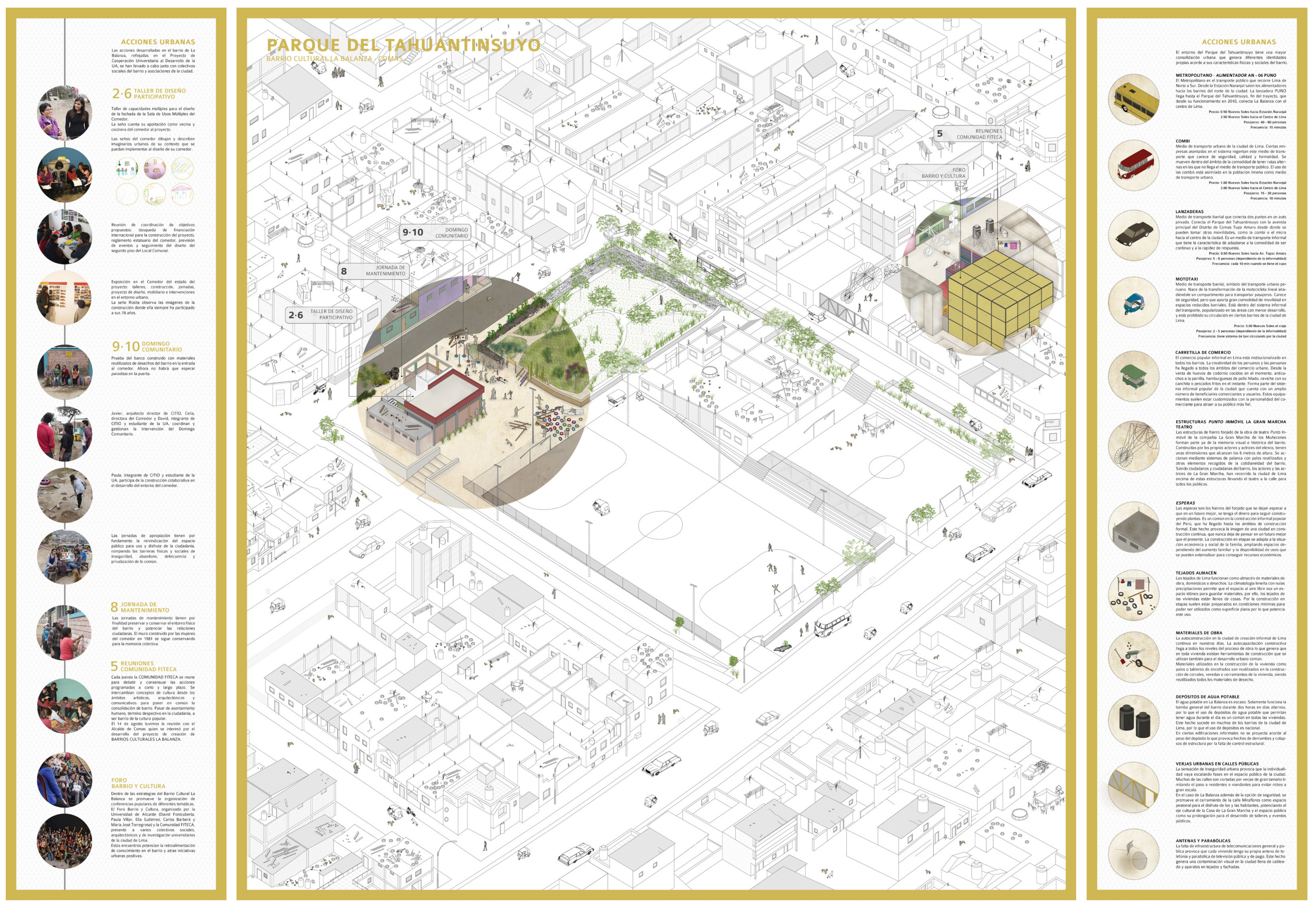




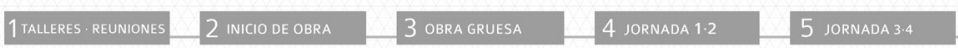
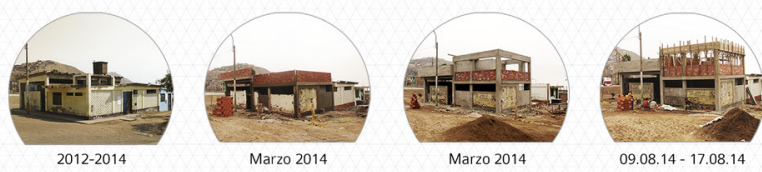

- $1-1$

are

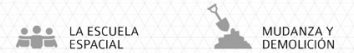

EstructuaA

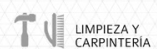

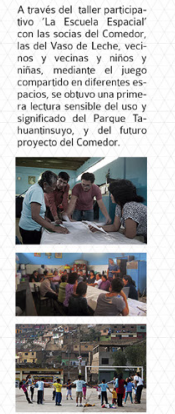

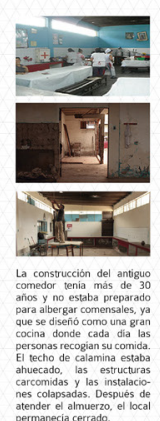

(ii)

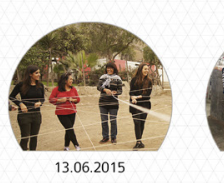

$(120$

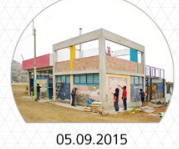

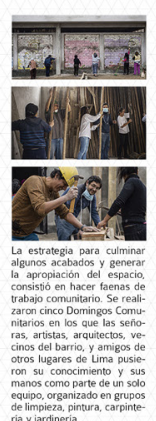

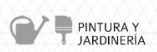

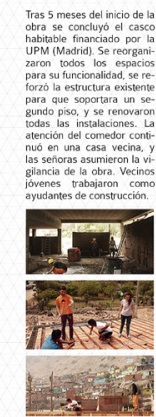

$=$
$=$
45

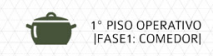

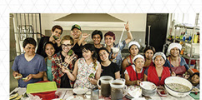

$=$

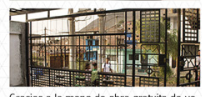

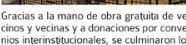

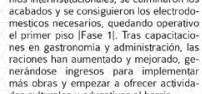

-

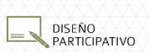

(1). DERATE DEL

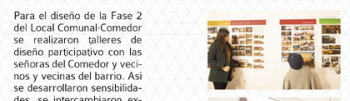

浆 13 . 政

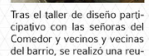

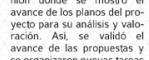

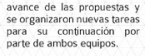

T)

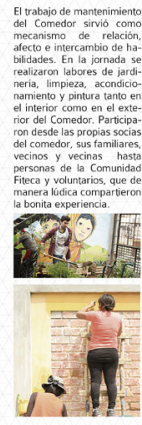

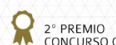

1.

준.

Yimis

and

$==2$.

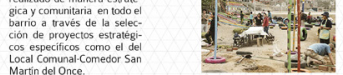

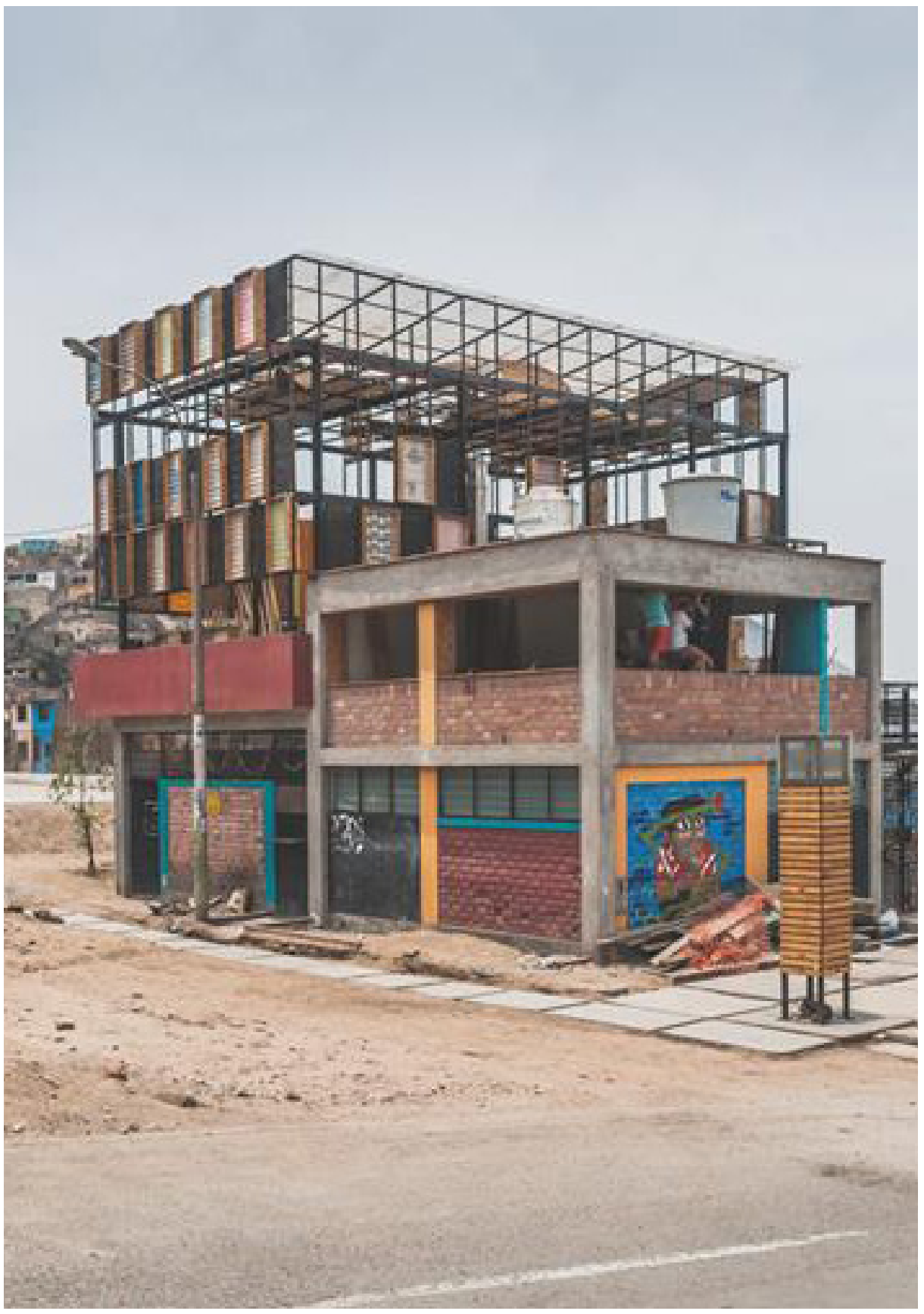

Línea de tiempo del Comedor Popular San Martín del Once Imagen de diciembre 2016. Barrio Cultural La Balanza |Limal 


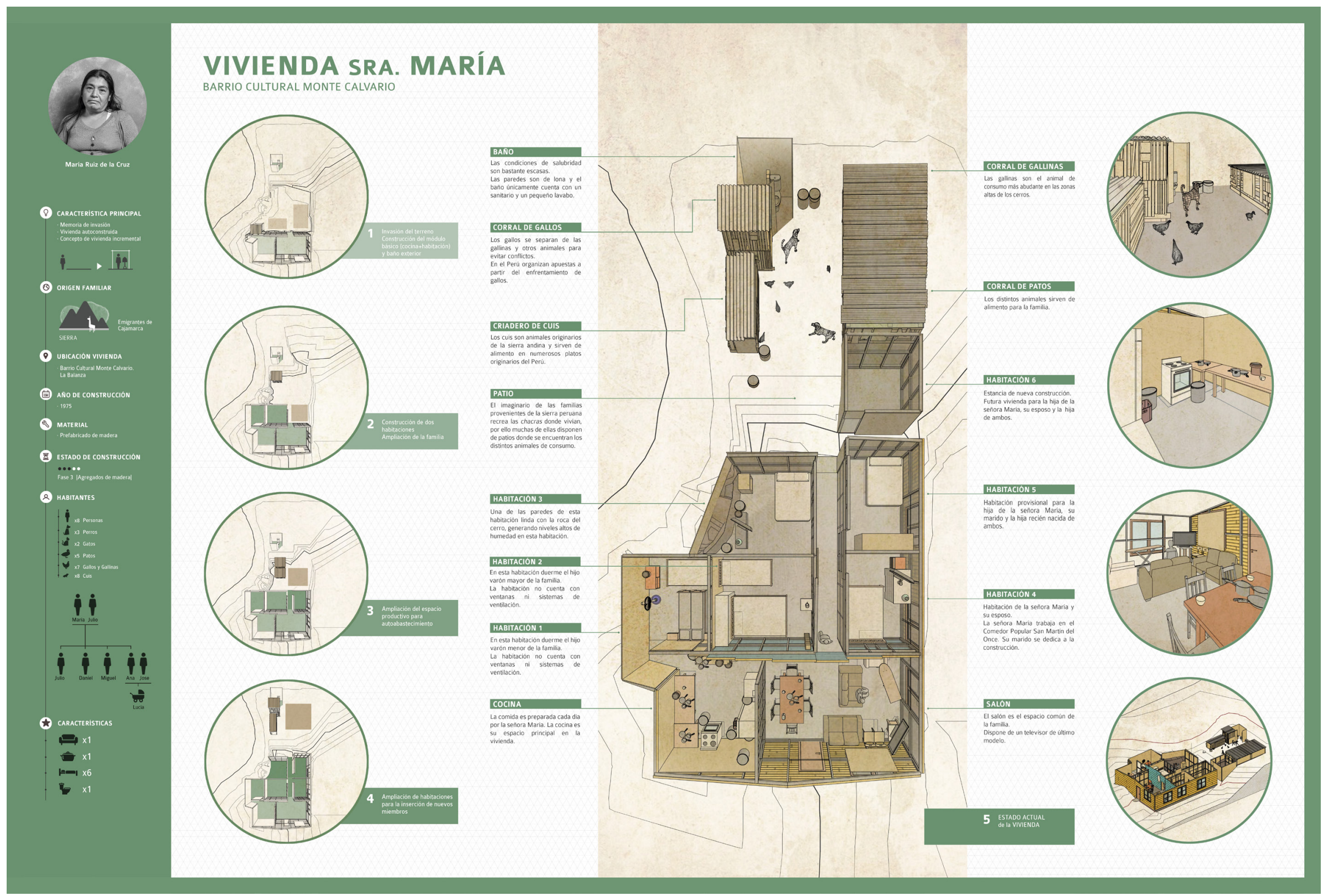




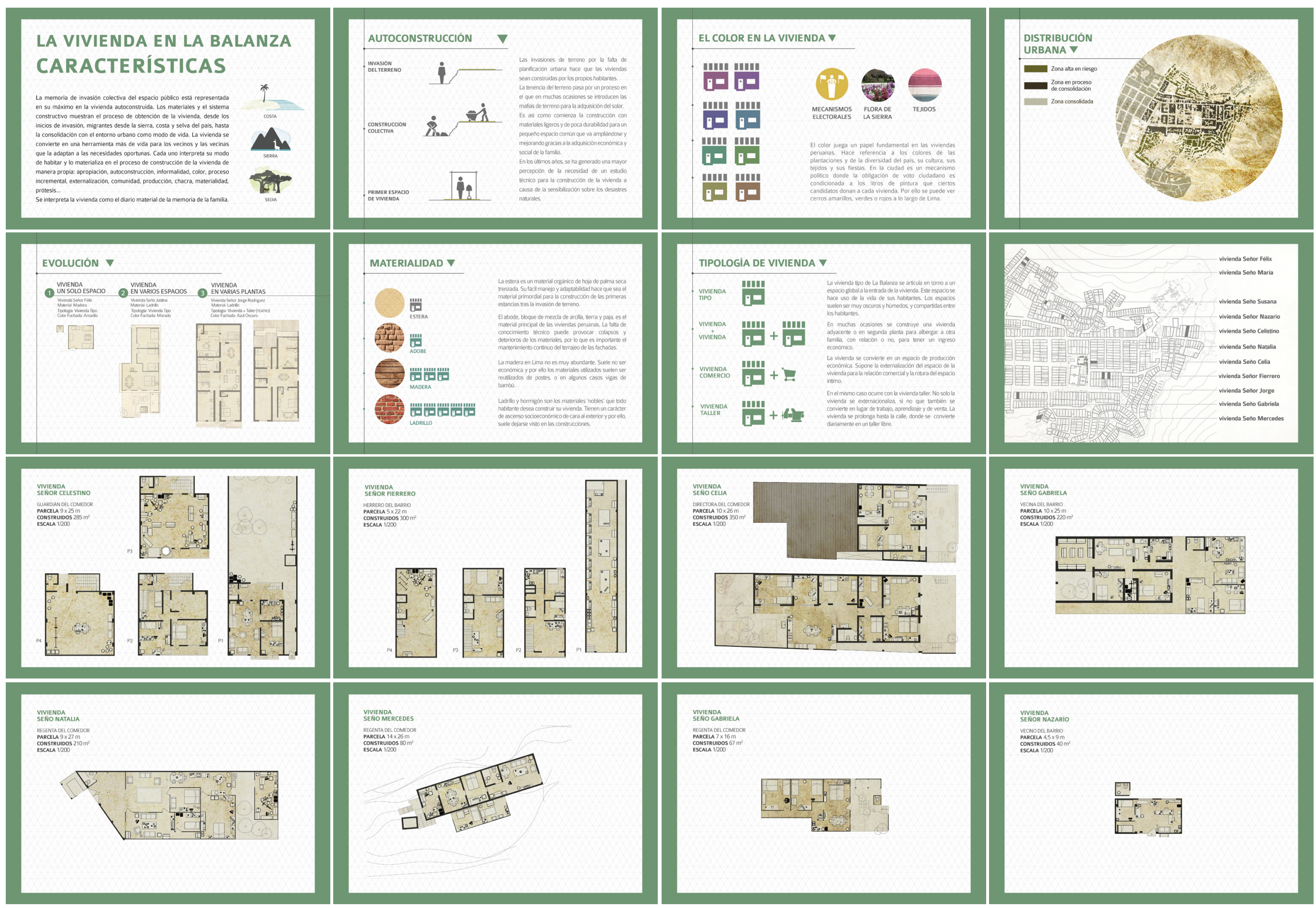



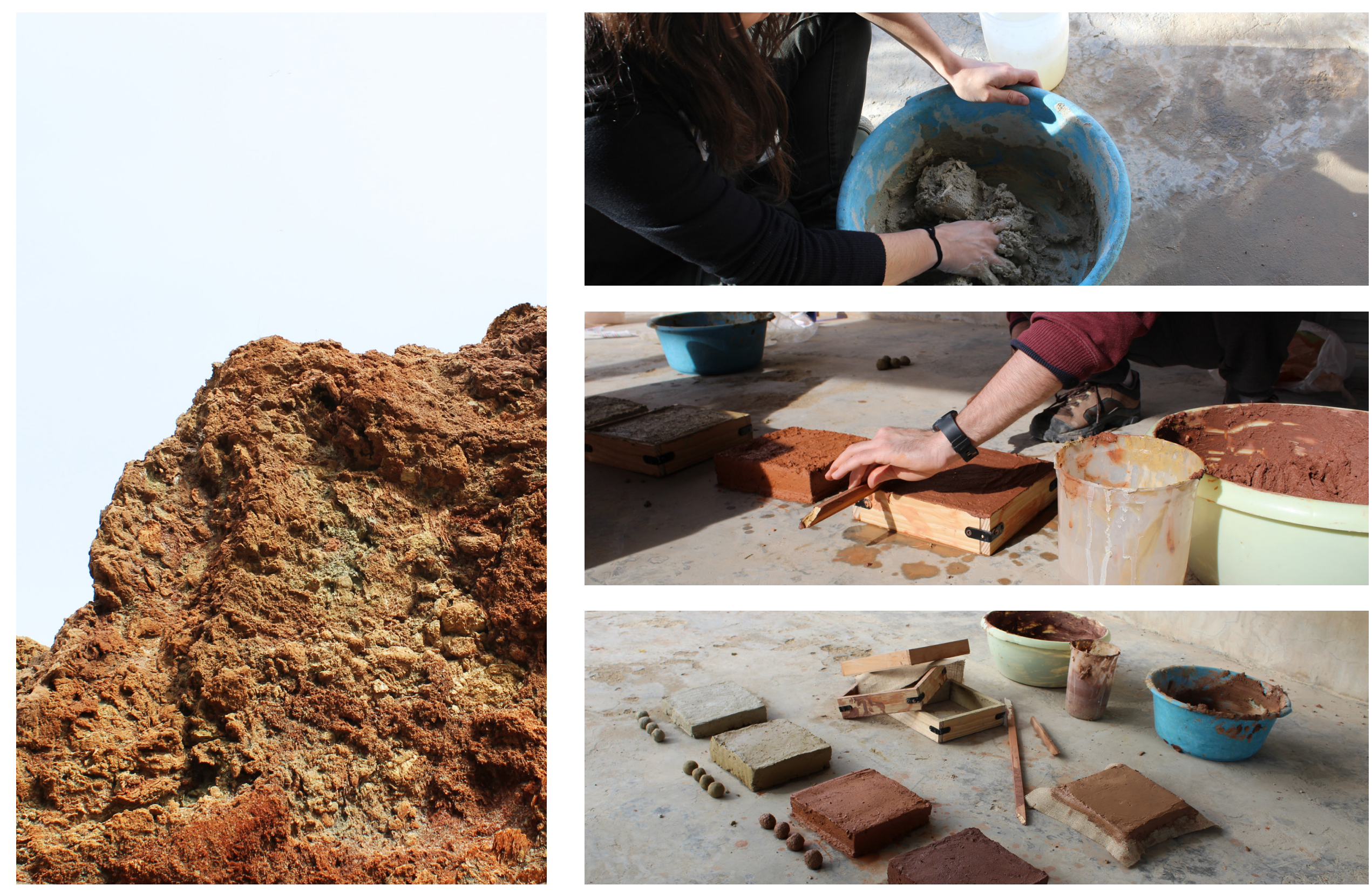

Puesta en práctica. Fabricación de adobes de tierra extraída del Monnegre. Alicante. 


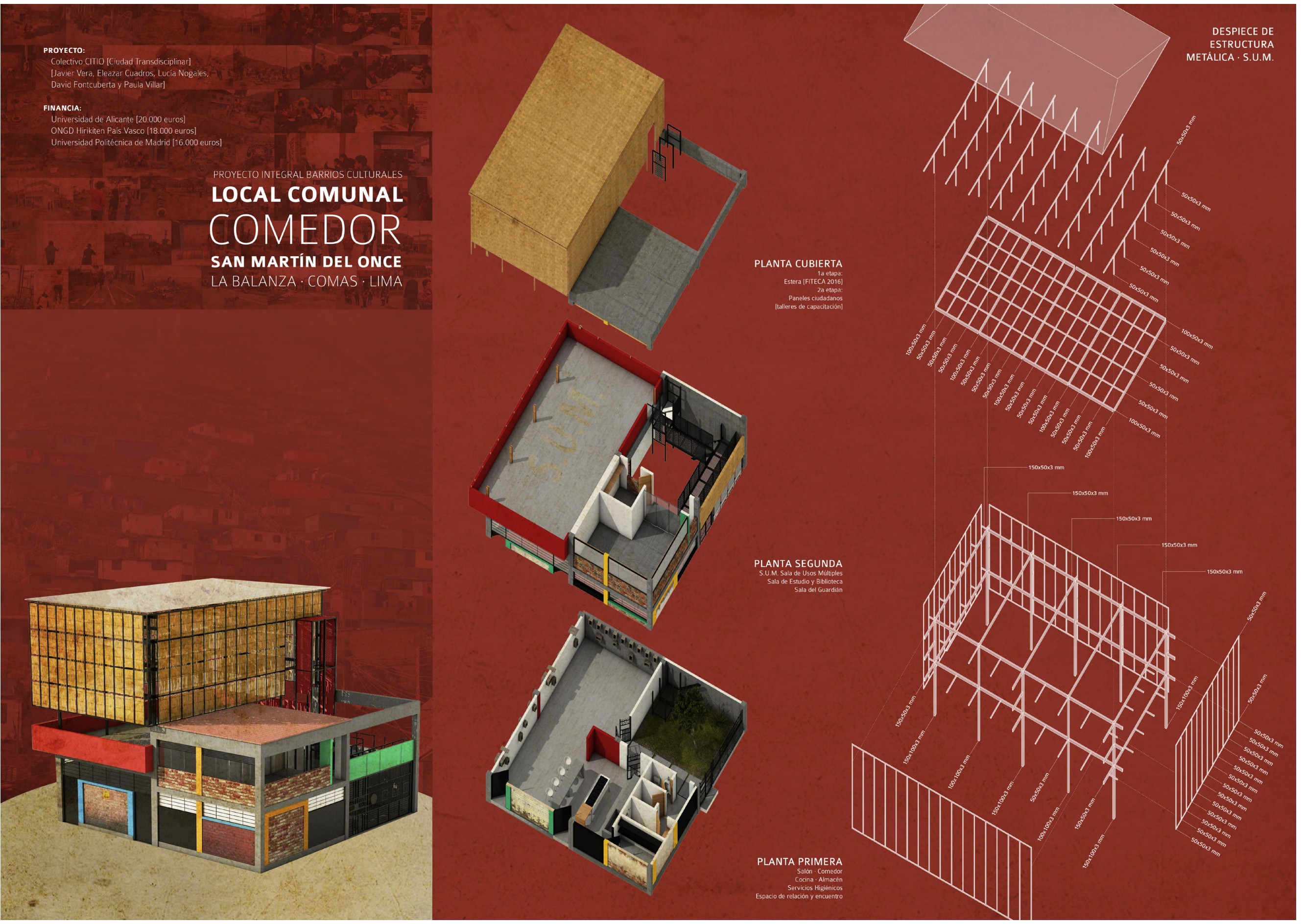




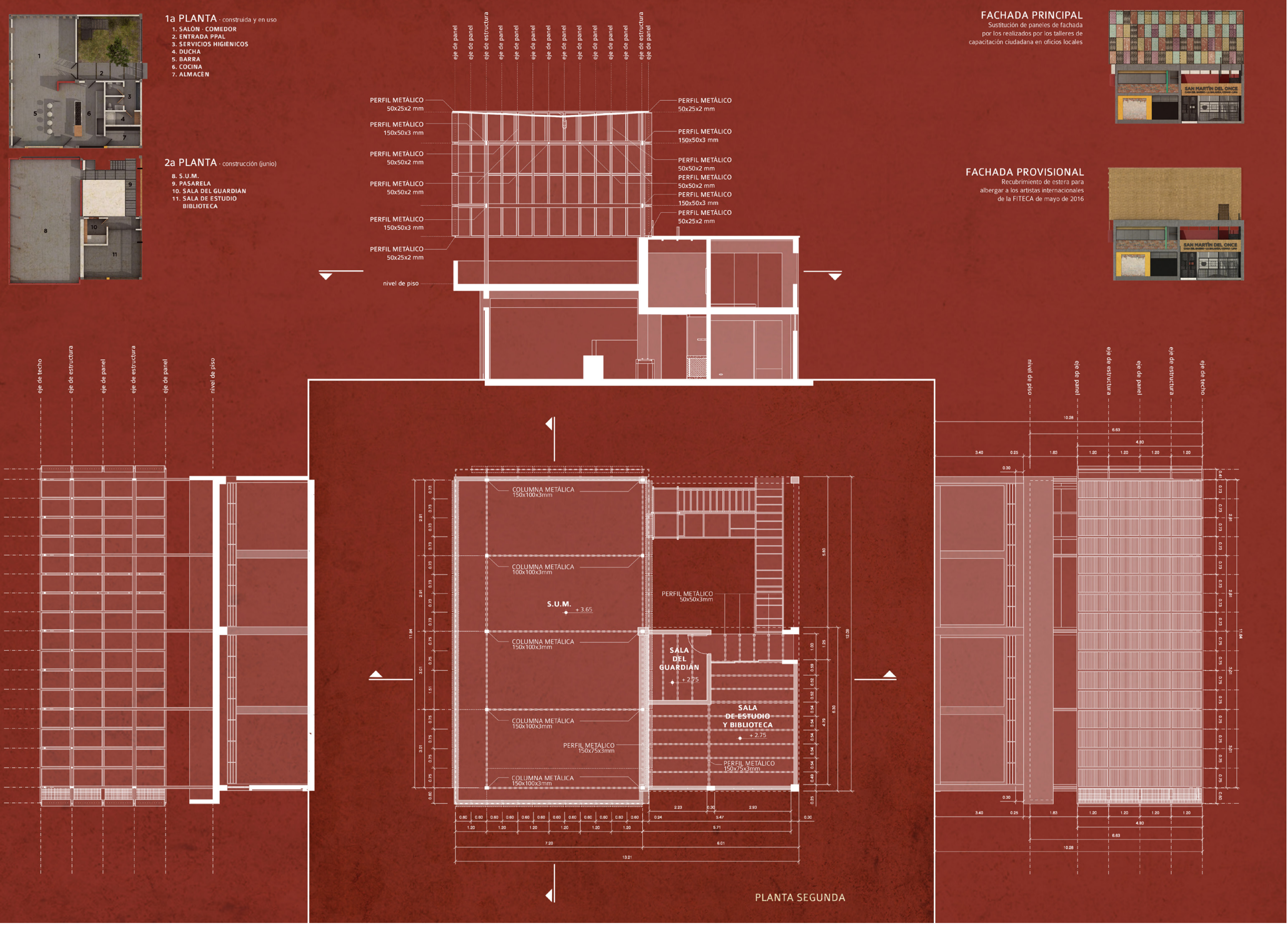




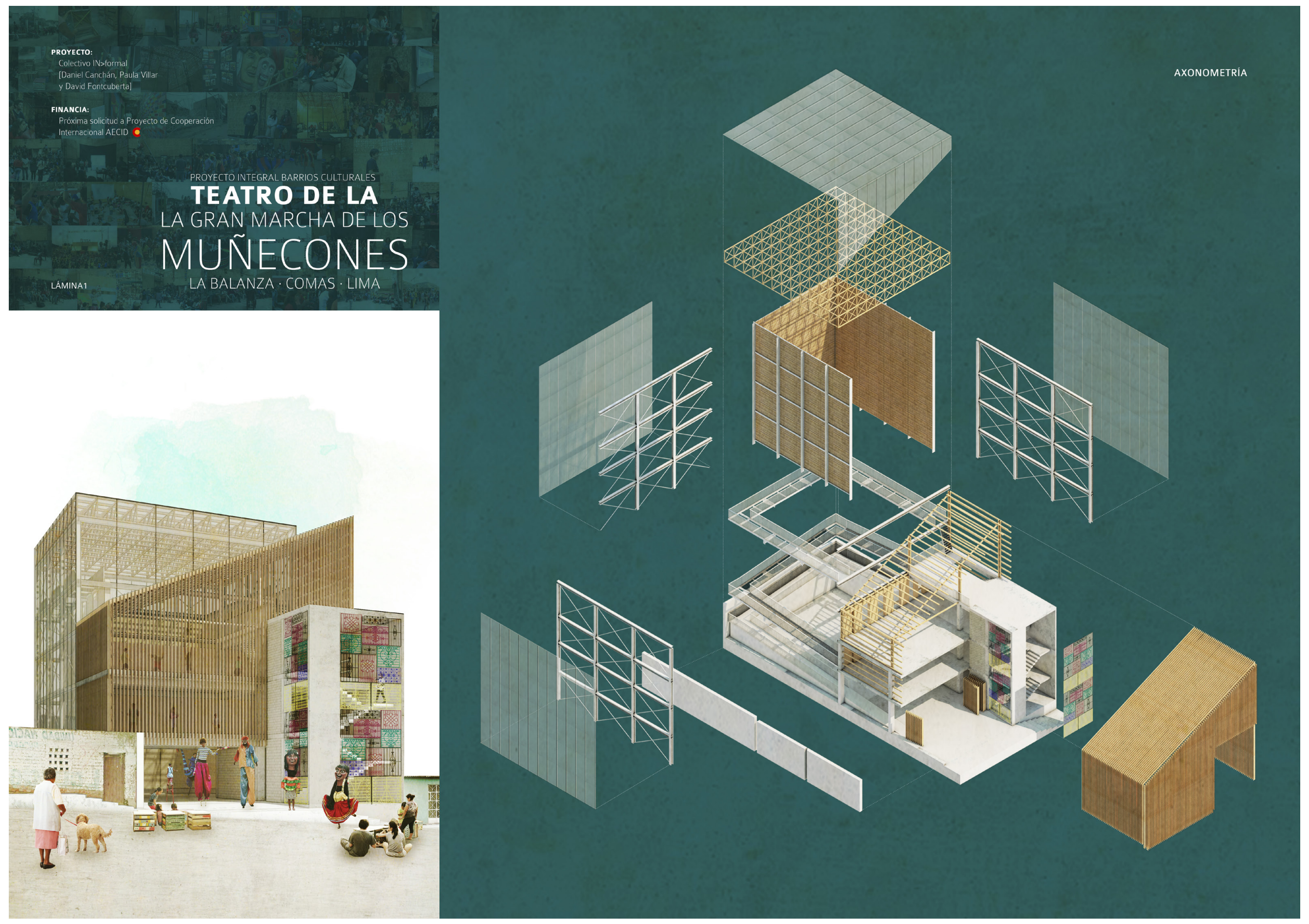




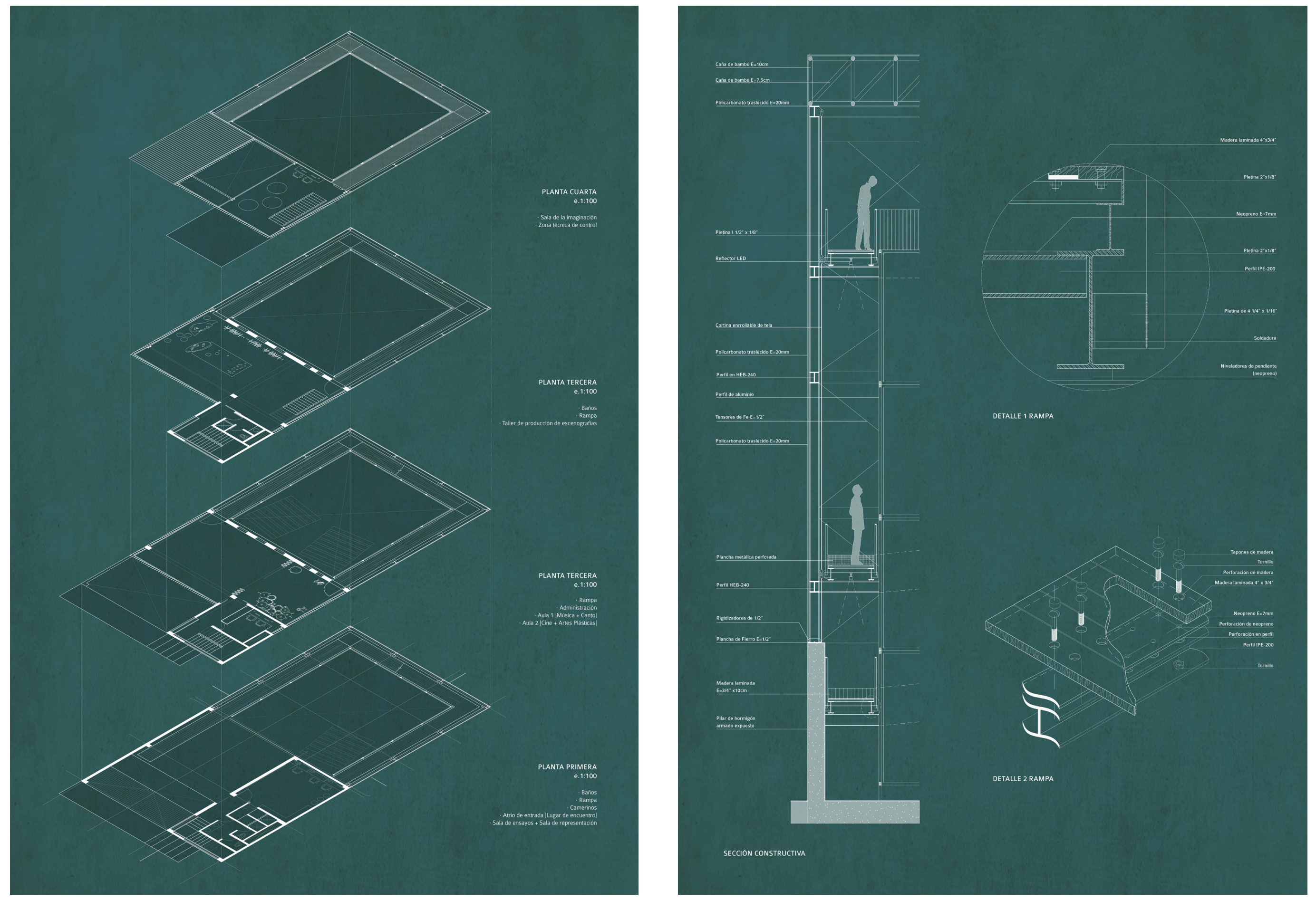


TEATRO DE LA LA GRAN MARCHA DE LOS MUÑECONES LA BALANZA . COMAS. LIMA

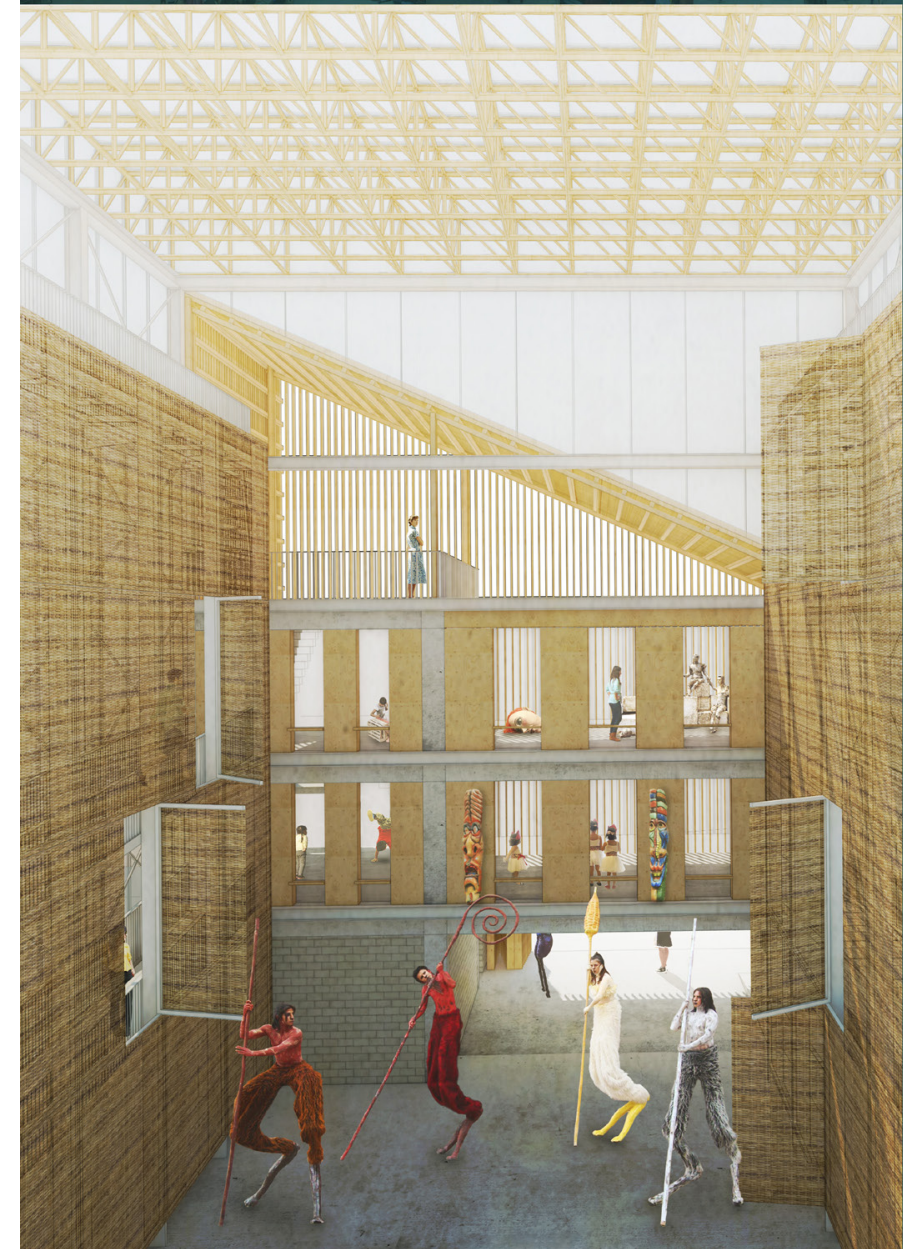

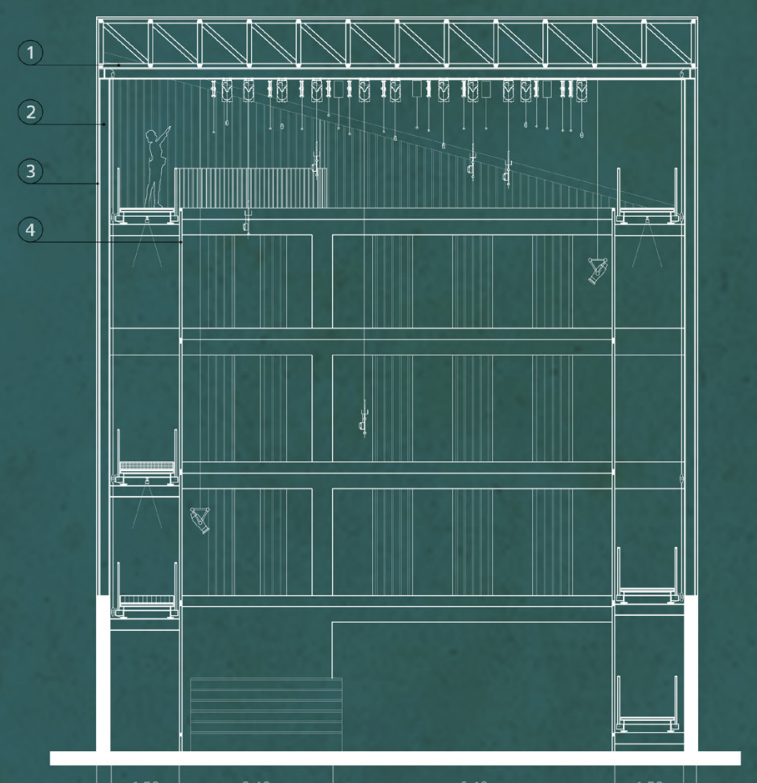

SECCIÓN TRANSVERSAL B. B'
e. $1: 100$

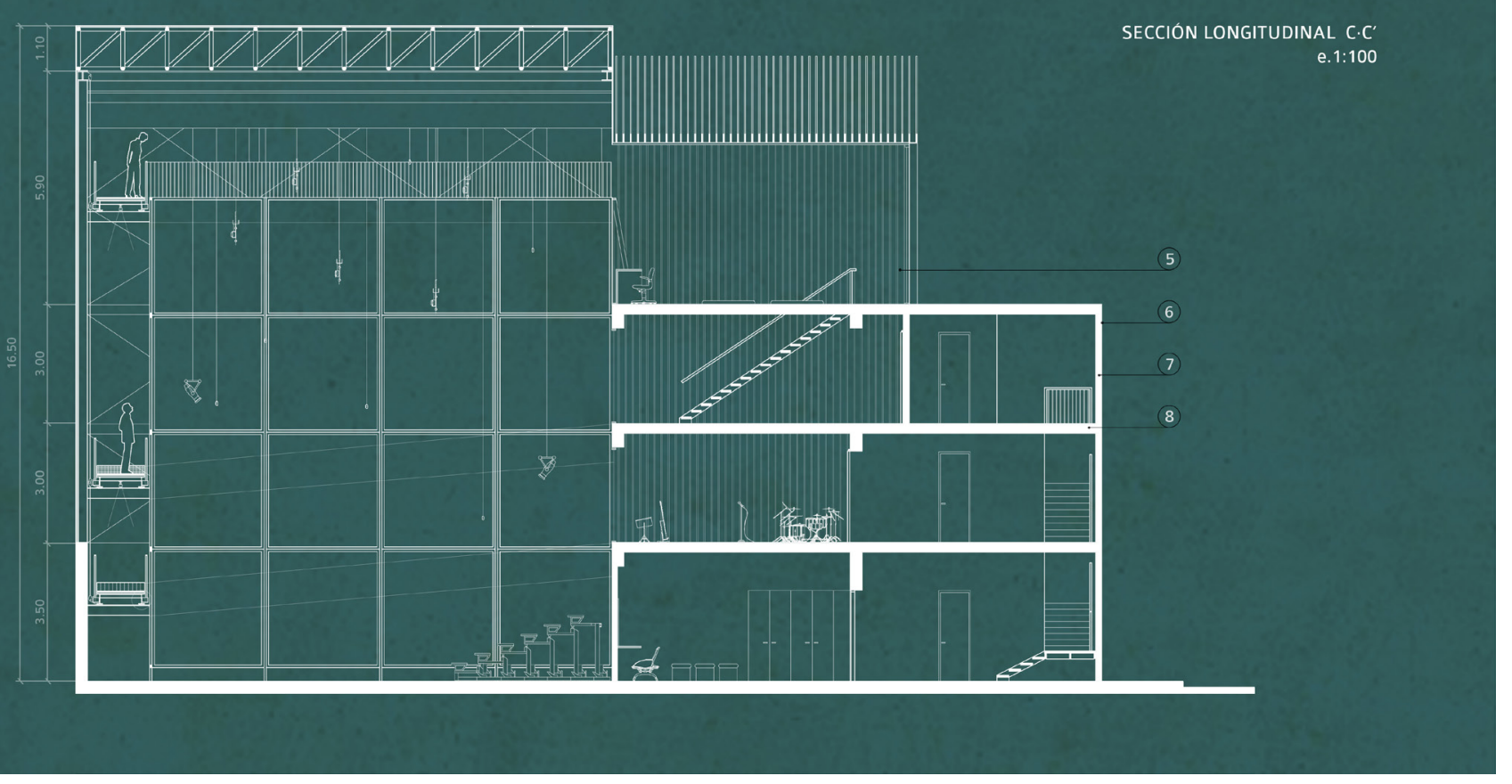



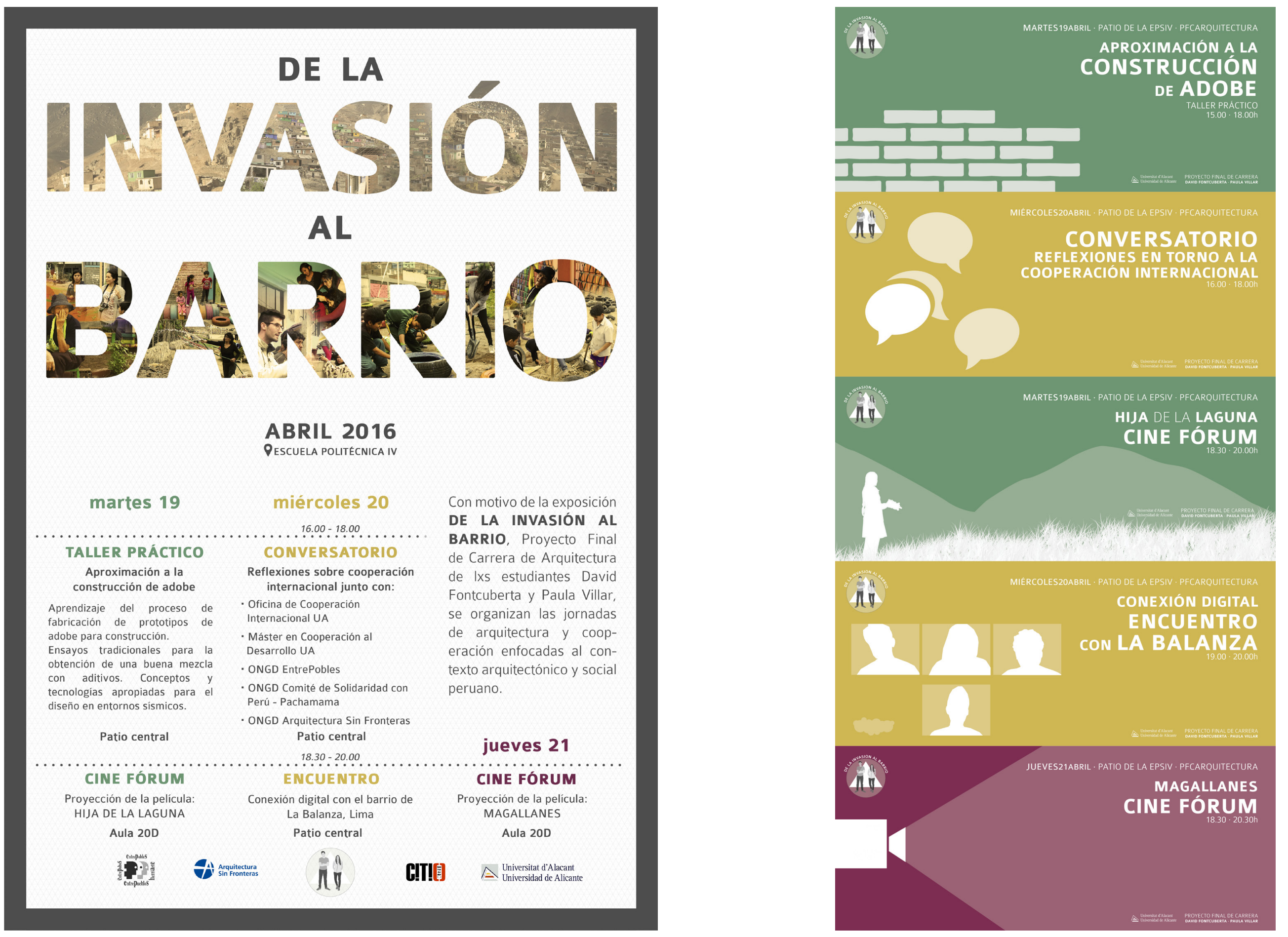

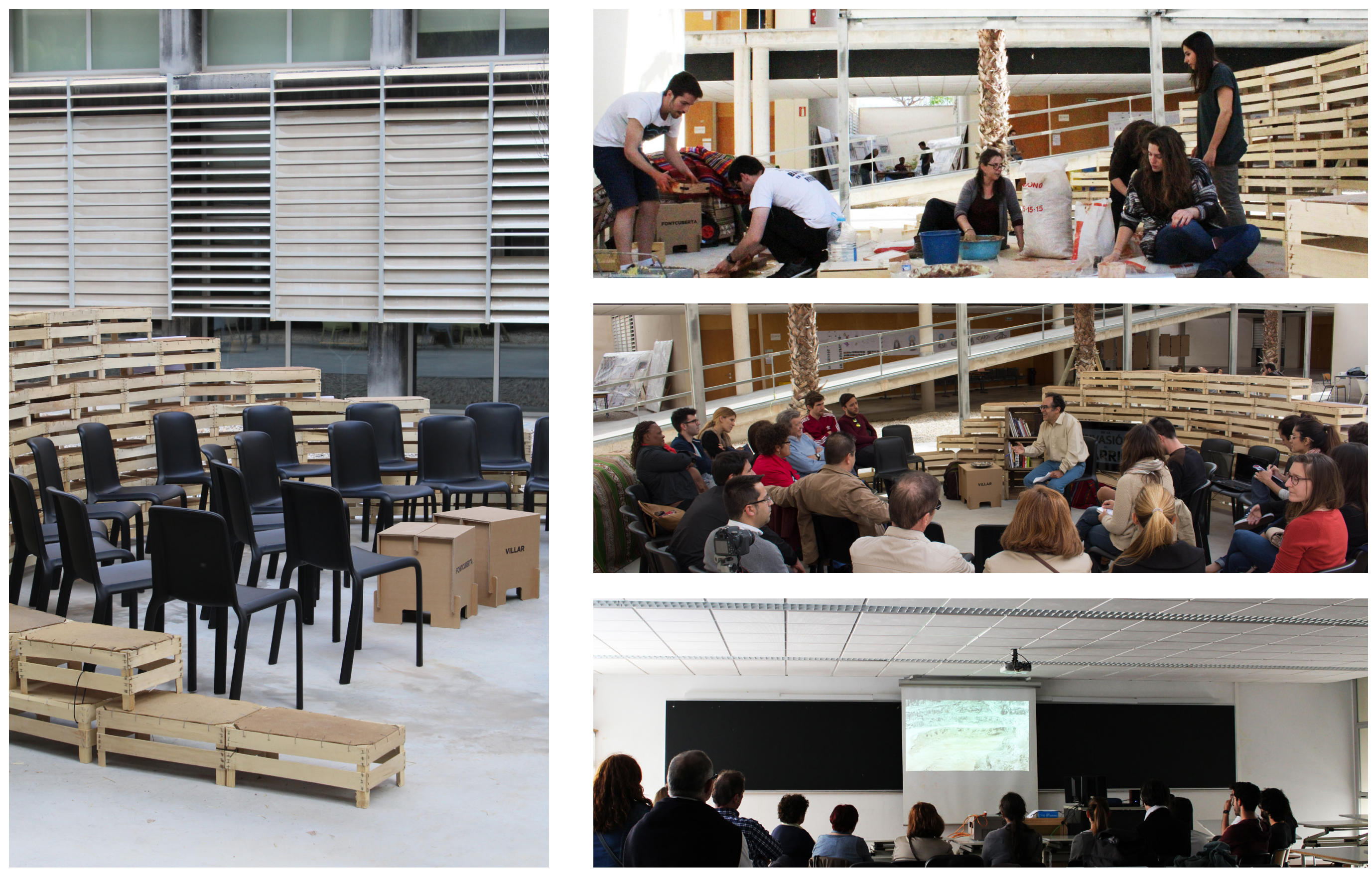


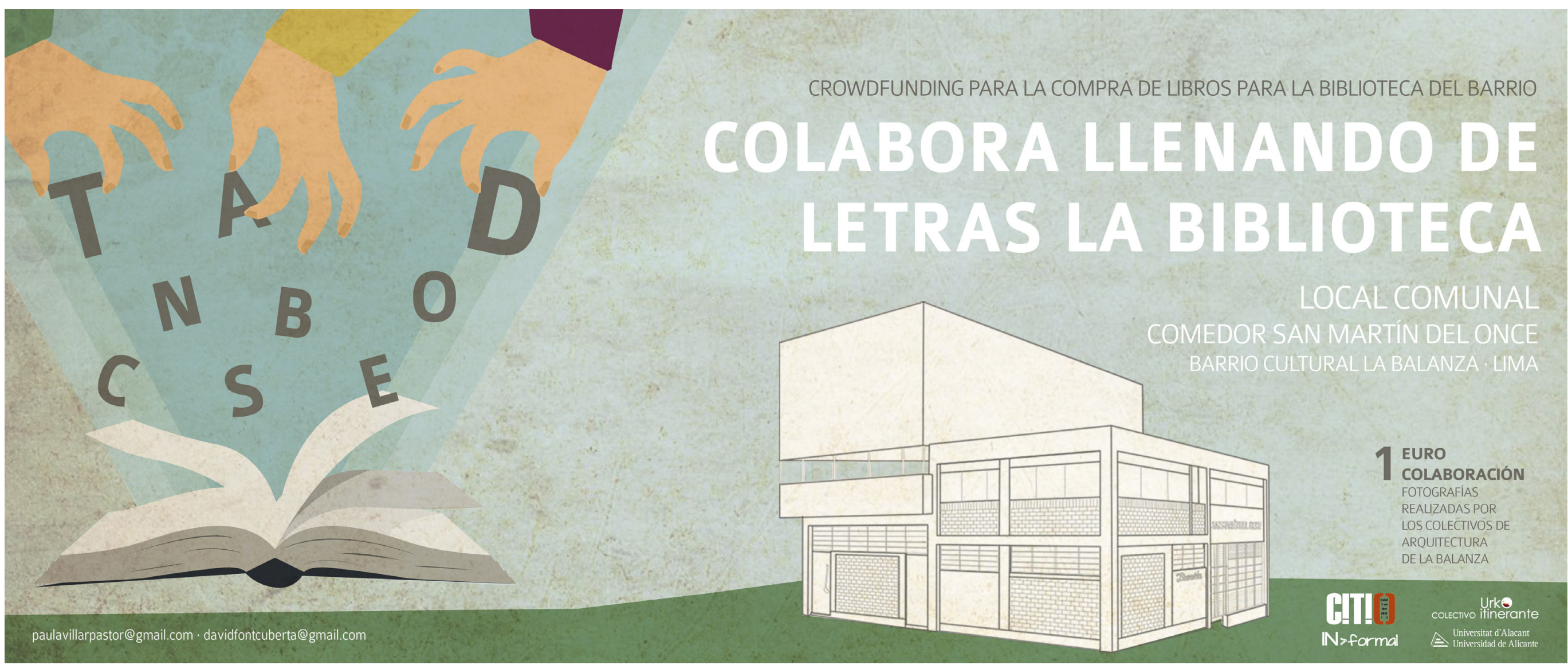

Crowdfunding para la implementación de libros en la biblioteca del Local Comunal San Martín del Once, Barrio Cultural La Balanza |Lima| 


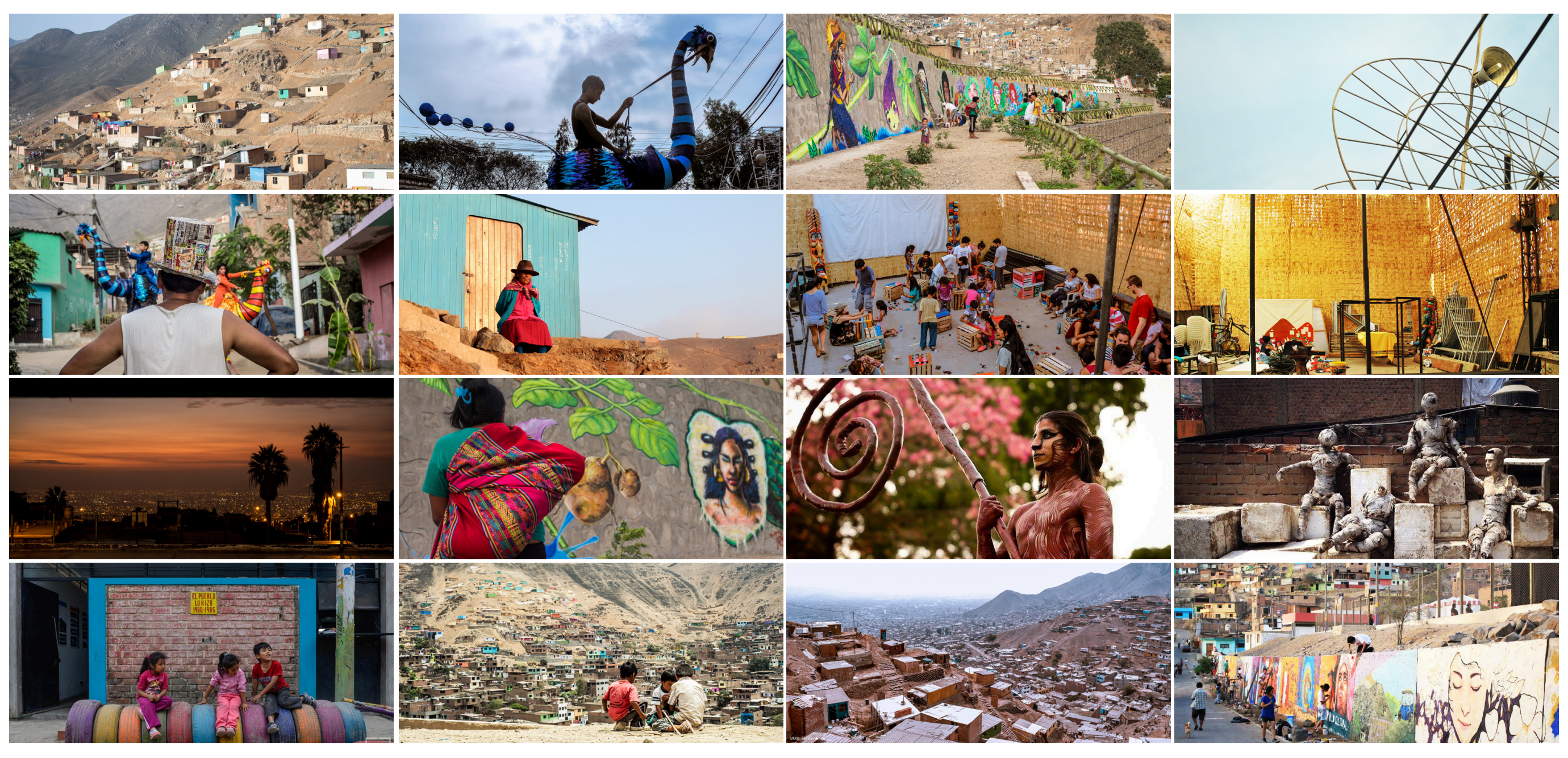


UNIVERSIDAD DE ALICANTE, OFICINA DE COOPERACIÓN UNIVERSITARIA AL DESARROLLO UA, JOAOUÍN ALVADO, ÁNGEL ALLEPUZ, ELIA GUTIÉRREZ, JOAOUUÍN ARNAU, MANUEL BLANCO, RAFAEL MUÑOZ, CARLOS BARBERÁ, MARÍA JOSÉ TORREGROSA, JUAN CARLOS RAMOS,

UNIVERSIDAD DE LIMA, ENRIQUE BONILLA, CRISTINA DREIFUSS, CAMILA GÁLVEZ, JOSÉ DEL CARMEN PALACIOS, ÁNGELES MAQUEIRA, MARINA VELLA, CITIO [CIUDAD TRANSDISCIPLINAR], JAVIER VERA, ELEAZAR CUADROS, LISSET ESCUDERO, LUCÍA NOGALES, GONZALO DÍAZ, LUCÍA NAVARRO, MARTA MACCAGLIA, NATALIA ADRIÁN, LIZ BALTASAR, PATRICIA HUAMANÍ, DIEGO SALDARRIAGA, PONTIFICIA UNIVERSIDAD CATÓLICA DEL PERÚ, SOFÍA RODRÍGUEZ-LARRAÍN, TERESA MONTOYA, PAULO DAM, MARTA VILELA, GRACIELA FERNÁNDEZ DE CÓRDOVA, ADRIANA SCALLETI, PABLO VEGA, MARIANA ALEGRE, WILEY LUDEÑA, DIRECCIÓN ACADÉMICA DE RESPONSABILIDAD SOCIAL DE LA PUCP, ZARELA ZAVALA, FAVIOLA CHÁVEZ, DIANA CRIBILLEROS, DEBRAH MONTORO, LOLA FERNANDA, RAOQUEL ENCISO, KATHIA, GABA, MILUSKA MAZA, LUCIANA CÓRDOBA, JOAN MACCHIAVELLO, MAYRA VILA, HILTER GONZÁLES, RENZO VALENCIA, WALTER NOEL, KATHERINE AGUIRRE, SHEYLA SALINAS, PEDRO RUIZ, CARLOS OUINTERO, MAURICIO GILBONIO, NADIA RODRÍGUEZ, JIMENA ÑIOUEN, NATALIA ELIAS, CLAUDIA NARVASTA, LUIS NORABUENA, JUAN VILLALÓN, SOJIN LEE, NEUS PASTOR, LA GRAN MARCHA DE LOS MUÑECONES, JORGE RODRÍGUEZ, PATRICIA BELTRÁN, ERNESTO MEZA TITO, MUJERES DEL COMEDOR SAN MARTÍN DEL ONCE, SEÑO CELIA, SEÑO MARÍA, SEÑO MERCEDES, SEÑO SUSANA, SEÑO ROSITA, SEÑO YOLANDA, DIRIGENTES DE LOS BARRIOS CULTURALES, RAFAEL RAUBINA, RAUL ROJAS, VECINOS Y VECINAS DEL BARRIO CULTURAL LA BALANZA, MUNICIPALIDAD DISTRITAL DE COMAS, COLECTIVO MI BARRIO LIBRE, MARTA ROMAY, CÉSAR ÁLVAREZ, ADELA TORRES, RENATO LÓPEZ, NÚRIA ROMAY, COLECTIVO IN>FORMAL, DANIEL CANCHÁN, JESSY ROJAS, LEYDI SÁNCHEZ, MARIELA CISNEROS, DIANA MONZÓN, ANDERSON GARCÍA, GIUSEPPINA MELI, CARLOS MORALES, WILSON GARCÍA, COLECTIVO URKO ITINERANTE, FÁTIMA ALVARADO, CARLA CORE, CESAR CARBAJAL, CRISTIAN MEZA, CHRISTOFER ALCÁNTARA, VÍCTOR RAMÍREZ, COLECTIVO INTUYLAB, JOSÉ CEPERO, FERNANDO DEXTRE, SEBASTIÁN PAREDES, ALEXA GUERRA, DEBORAH TRAPUNSKY, PIERI SÁNCHEZ, COLECTIVO BARRIOS ARTES, JOCELYN CUETO, CAMILA HARMAN, VLADIMIR VICENTE, COLECTIVO EL CARTÓN, CARLA POMA, JOSÉ LUIS CHANGO, COLECTIVO SOMOS MINKA AUDIOVISUAL, COLECTIVO RUWASUNCHIS, LINDA VELÁSOQUEZ, MARC SAMANIEGO, JUAN DIEGO CALISTO, COLECTIVO PASAJE 140, MARLON ARIZA, MIGUEL ÁNGEL NEOLA, CÍRCULO DE ESTUDIOS URBANOS, RODRIGO CIEZA, CAROLINA NEUHAUS, DIEGO NÚÑEZ, NIA FLORIAN, RAMIRO PASCAL, ISABEL RAMÍREZ, CLAUDIA GÓMEZ, NELLA RAMOS, COLECTIVO TOMAELBYPASS, GENARO ALVA, MARIANELA CASTRO, HERMANOS MARISTAS DEL PERÚ, ROSA AVILÉS, BLANOUUITA, JUNIOR PINTADO, CÉSAR RAMOS, EDUARDO GUERRERO, LUIS AGURTO, TANIA YESEÑA, GIANCARLO CRISANTA, GLORIA CUBAS, SEÑO ROSITA, MARTÍN ARTEAGA, ANDREA VALLEJOS, MARLENE SOTOMAYOR,

MANUEL CALVO, ANA MOLES, ANA VAN DER HOFSTADT, VICTORIA GOSÁLBEZ, AITOR PINILLA, CELIA MARTíNEZ, FABIOLA MURCIA, SONIA AMORÓS, VALERIA MORALES, JANA MARCO, MIGUEL MARTÍN, VERÓNICA LUGLI, CRISTINA ORTEGA, SANTIAGO VILLAR, PAULA RODRÍGUEZ, GRUPOFAMILIA, ESTEFANÍA SOLER, BEATRIZ MORENO, ANA GUTIÉRREZ, MARTA ESPADA, MAR LÓPEZ, MIGUEL MANZANO, ALEJANDRO MCAULEY, ELISA PÉREZ, AROUUTECTURA SIN FRONTERAS, JOSE LUIS OLIVER, ANDRÉS MARTÍNEZ MEDINA, ANTONIO MACIÁ, PENCHO SÁNCHEZ, VICENTE IBORRA, IVÁN CAPDEVILA, CARO MOYANO, JOSE MOYANO, DANIEL MILLOR, ESTER RAMÓN, CARMEN SOFÍA LINARES, ADRIÁN LÓPEZ, ALMUDENA ESCRIBANO, ALBA GARCÍA, MARÍA JOSÉ PACHECO, MERCEDES CAMPELLO, JESÚS ALBADALEJO...

...Y POR SUPUESTO, ESPECIAL AGRADECIMIENTO A NUESTRAS FAMILIAS, QUIENES HAN CONTRIBUIDO EN TODOS LOS SENTIDOS AL DESARROLLO DEL PROYECTO, DE LA INVASIÓN AL BARRIO. 